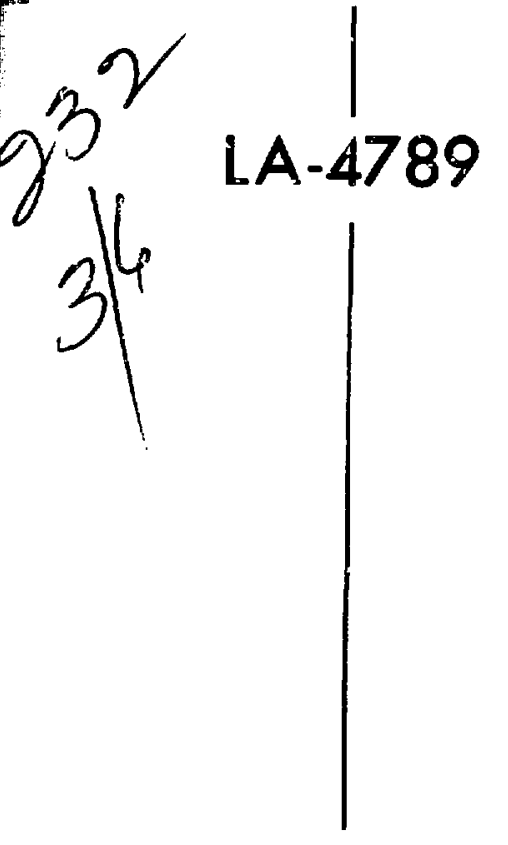

2061

Neutron Production by Medium-Energy Protons on Heavy Meral Targets 
This report was prepared as an account of work sponsored by the United States Governmerit. Neither the United States nor the United Siates Atomic Energy Commission, nor any of their employees, nor any of their contractors, subcontractors, or their employees, makes any warranty, express or imDíeci, or assumes any legal liability or responsibility for the accuracy, comsieteness or usefuiness of any information, apparatus, product or process disclosed, or represents that its use would not infringe privately owned rights.

This report expresses the opinions of the authrir or authors and does not necessarily reflect the opinions or views of the Los Alamos Scientific Laboratory.

Printed in the United States of America. Available from National Technical Information Service

U. S. Department of Commerce

6285 Port Royal Road

Springfield, Virginia 22151

Price: Printed Copy \$3.00; Microfiche \$0.95 

makes any untor, subcontractors, or their employees, legel liabllity or respongibility implied, or essumes any pleteness or un responsibility for the accuracy, completeness or usefulness of any information, product or process disclosed, or represents that atus, would not infringe privately owntd rights.

\section{Neutron Production by Medium-Energy Protons on Heavy Metal Targets}

by

R. R. Fullwood

J. D. Cramer *

R. A. Haarman **

R. P. Forrest, J\},

R. G. Schrandt

"Present address: Science Applications, Inc., La Jolla, California 92037.

- "Present address: General Electric Co., Arco, ldaho 83213. 
CONTENTS

Abstract 1

I. Introduction 1

II. Motivation 2

III. Nucleon Cascade-Evaporation Model 2

A. Review of the Mucleon Cascade Model 2

B. Review of the Evaporation Model 4

c. Experimental Tests of the Nucieon Cascade-Evaporation Model 5

IV. Computational Procedure 6

A. Nucleon Meson Transport Code NMTC 6

B. H1gh-Energy Neutron Spectra 7

C. Low-Energy Neutron Spectra 7

D. Gamma-Ray Specira 7

E. Alternative Neutron Transport Calculation 8

v. Compartson and Results 8

VI. Compartson of the $(p, x n)$ Source with the $(e, \gamma, x n)$ Sourze 17

VII. Conclusions 20

Acknowledgments 20

Appendix A: Cross-Section Extrapolation Techniques Used by Schrandt, Cramer, and Beyster 20

Appendix B: Tebulated High Energy Data 21

$\begin{array}{ll}\text { ReEerences } & 27\end{array}$ 
NEUTRON PRODUCTION BY MEDIUM-ENERGY

PROTONS ON HEAVY METAL TARGETS

by

R. R. Fullwood, J. D. Cramer, R. A. Haarman,

R. P. Forrest, Jr., and R. G. Schrandt

\section{ABSTRACT}

Neutron production resulting from medium-energy proton bombardment of heavy metal targets was calculated by Monte Carlo methods for cyinders and a sphere as a function of time, angle, and position. With one exceptlon ( $550 \mathrm{MeV}$ ), all calculations were for $300-\mathrm{MeV}$ proton energy and for targets of ${ }^{238} \mathrm{U}$, lead, tantalum and $a{ }^{238} \mathrm{U}-23 \mathrm{C}_{U}$ composite. Gamma-ray production w.as calculated by a simplifled model and the results were cowpared with those of Alsmiller and Moran for gamma-ray production for a 150-MeV electiron bombariment of tantalum.

The ratio of escaping neutrons per incldent proton $(n / p)$ varled from 38.5 to 16.7 depending upon the target. The results reported here give $\mathrm{n} / \mathrm{p}$ ratios for uranfum about $25 \%$ lower than that reportad by the workers on the Canadian Intense Neutron Generator (ING) project. Ninety percent of the evaporation neutrons that serve as the source fm the low-energy neutron transport are produced within a $0.75-\mathrm{cm}$ adjus of the ioam and have an axial distribution so that $63 \%$ are con'alned within. a 12.3-c\% length. This fact is manifest th :ough the comparative insensitivity of neutron production to target geometry. The vost probable energy for the secaping neutions from the large targets 18 about $0.2 \mathrm{MeV}$ resulting from the degradation of the evaporation spectrum by neutron inelastic and multiple production processes. For the large ${ }^{23} \mathrm{U}$ targets, there vas one escaping photon for every 12 escaping neutrons. This low ratio is a consequence of the strong photon absorption tn the target and the mechanisa of neutron production.

Because the efficecy of this neutron production metho Sepends cn the strength of avallable proton sources, a comparison is made of a proposed facility time-sharing the beam of the Los Alamoe Keson Physics Facility (LAMPF), the 1mroved Columbia University Nevis Gyciceron's axpected performance, and the Oak RIdge National Laboratory Electron Linear Accelerator (ORELA).

\section{INTRODUCTION}

Neutron production by medium-energy proton bombardment of heavy metal targets recelved conslderable attention in the Cenadian Intense Neutron Generator (ING) study. The Los Alamos Kenon Physics Facility (LAMP) has a different ootivation, but will have proton currents, durlng the pulse, 257 of those of the ING study and at nearly tha san enorgy ( $800 \mathrm{MeV})$. Because of different requirements, the otudy for
LAMPF has been toward a low-duty intense neutron burac facility, therefore the emphas has bean on uranium targete for their high dentity and highneutron-to-incident-proton ratlo rathar than on the lower heat generating biaruth targets of the IMG study.

This report is orgenized at follow. Section II 18 discugston of neutran production by sidium energy proton bowbardant of thick targets. 
Section IIJ gives a description of the two-step nucleon cascade-evaporation model for generating highenergy ( 25 Mev) cross sections. The assumptions, 11mitations, and experimental tests of the model are also discussed. Section IV is a discussion of the Monte Carlo program Nucleon Meson Transport Calculation (MMTC) that computes the transport of particles between nuclear Interactions and applies the continuous slowing-down approxdmation to the transport of charged particies down to a cutoff energy. A utillty program follows, High Energy Analysis (HIANAL), that groups the cascade and evaporation neutrons according to eriergy, angle, and position to serve as input data to a general purpose, Monte Car20 Neutron (MCN) transport code, or to GAMGEN for gamma-ray generation and subsequent transport in the Monte Carlo Gamma transport code (MCG). All of these codes use evaluated cross sections. Following this, the output of MCN is grouped in the utility program, Low Energy Analyals (LOANAL), that correlates the escaping neutrons according to energy and angle. Similarly, the gamma output is correlated in GAMANAL. Section $V$ gives comparisons with neutron spectrum experimente and other Monte Car1o calculations to establish the validity of tisese calculations. Following this, data are presented on the nestron spectra as a function of angle, energy, and target radius for ${ }^{238} \mathrm{U}$ targets. Spectrum tafloring is inveatigated by comparison with lead targets as well as a ${ }^{235} \mathrm{U}$ sleeve. Data are presented for target heating as well as the time, energy, and spatial depeadence of emlssion. Finally, garma-ray production data sre given. Section vI compares the $(p, x n)$ source based on the LAMPF accelerstor and the Nevis cyclotron with the $(6, \gamma, x n)$ source as exemplified by the Oak Ridge Electron Linear Accelerator (ORELA). Appendfx B gives the MMTC output with suggestions for extrapolation of the data in energy and atomic number. These data way be used as a source Input to a transport calcrilation.

\section{MOTIVirION}

The production of neutrons by meálum-energy proton bowhardment of lead targets has been explofted for neutron time-of-flight experiments at the Columbla Univers1ty Nevis Synchrocyslotron for many years. The lack of general acceptance of this technique is attributed ${ }^{1}$ to woing these accelerators for other purposes and the consequent desire to retrove the pulsed structure. Also another source, the electrun linac, is avallable at a lower cost.

However, during the last decade, there has been a study of intense neutron sources at varfous laboratories. It 18 expested that ultimately the neutron sources using reactions that generate the least amount of target heating per neutron will dominate. Table I (Ref. 2) summarizes various reactions for this puipose and indicates that only (d,t) fuston is more efficlent than $(p, x n)$. Figure 1 (Ref. 3) Indicates by experimental data that the $(p, x m)$ production is strongly energy dependent, with a knee occurring at about $800 \mathrm{MeV}$. Figure 2 (Ref. 3) shows the ratio of neutrons/1nctdent proton as a function of proton energy and target materlal. From these figures it wight seem that the highest Incident energles posstble would be desired. However, as pointed out by Havens, ${ }^{1}$ geometric factors must be considered. For most experimeats, a high luminosity ( $/ \mathrm{cm}^{2}$ ), minlinum spatial uncertainty, and minfmum burst time varlance are equally destrable. These factors are favored by low-energy beams and the highest posalble target densities. The combination of fastors would Indicate that $800-\mathrm{MeV}$ protons inctdent on thick ${ }^{238} \mathrm{U}$ target.s would be very favorable for pulsed neutron experimentation.

III. NUCLEON CASCADE - EV.APORATION MODEL A. Review of the Nucleon Cascade Model

Serber ${ }^{4}$ shows that, as the energy of an Incident particle is increased, a taxget nusleus becomes

TABLE I $\mathbf{I}^{a}$

TARGET HEATING AND NEUTRON PRODUCTION EFFICIENCX

\begin{tabular}{|c|c|c|}
\hline Reaction & $\begin{array}{l}\text { Target Heating } \\
\text { (MeV/a) }\end{array}$ & $\begin{array}{l}\text { Neutron Production } \\
\text { Eff1 efency } \\
(\mathrm{n} / \mathrm{M})\end{array}$ \\
\hline $\begin{array}{l}\mathrm{T}(d, n)^{4} \mathrm{He} \\
(250 \mathrm{keV})\end{array}$ & 2500 & $2.4 \times 10^{25}$ \\
\hline $\begin{array}{l}v(e, \gamma, x n) \\
(35 \text { HeV })\end{array}$ & 2000 & $=10^{15}$ \\
\hline${ }^{9} \mathrm{Be}(d, n){ }^{10} \mathrm{~B}$ & 1200 & $\times 10^{15}$ \\
\hline Flesion & 200 & $3 \times 10^{16}$ \\
\hline $\begin{array}{l}B 1(p, x) \\
(1 \mathrm{GeV})\end{array}$ & 23 & $2.6 \times 10^{27}$ \\
\hline T, d Fusion & 3 & $\times 10^{10}$ \\
\hline
\end{tabular}

Fron Ref. 2. 


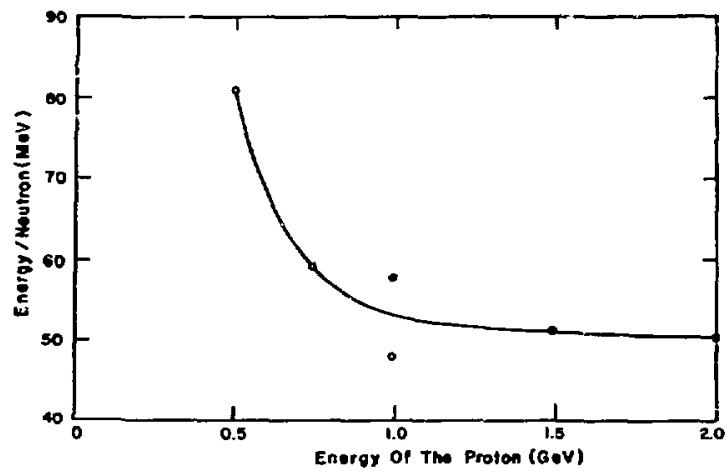

F1g. 1. Energy required to release a low-energy neutron by medium-energy proton bombardment of a thick (24-1n.) lead target.

transparent and the reactions take on the character of free nucleon collietons in a cegenerate Ferml sea. The forward momentum transfer $\bar{h} / a$ (a 1a the range of nuclear forces) is a constant and only a small fraction of the energy of the incident particle is removed with each collision, hence a cascade develops. The problen is to follow the trajectorles of colliding free particles in the nuclews, subject to the constralat of the Pauli exclusion principle, unt1l thay escapo leaving an exclted nucleus that deexcltes through particle evaporation.

$$
\text { Goldberger }{ }^{5} \text { and others }{ }^{6-12} \text { implemented this }
$$

Idea through Monte Carlo techniques but were IImited by computational methods. Metropolis et al. ${ }^{13}$ made refinements and applled an electronic computer (MANIAC) to the problem. FIgure 3 shows the procedure followed to chart the hlatory resulting from a particle 1ncident on the nucleus. Bertinit ${ }^{14}$ further refi:ed the model and coded tite problem in FORTRAN for a comerctal computer, which greatly increased ito untversallty. The nucleon cascade model is used to generate "crose-section" data In a general Monte Cerlo program (NhIC ${ }^{15,16}$ ) that treate particle tranaport in large system. In application to the problem of thick targeta, an internuciear cascade 18 Involved. The MMTC proyran was adapted to the CDC 6600 computar by H. I. Israel (LASL Group B-1) and wes applied to all the calculations in thle report.

Before leaving the discuetion of the Intranucleat cascade as treatsd by Bertint, we liet the phyoleas counlderations of the theory.

1. Abova a certain cutoff enorgy (telen here

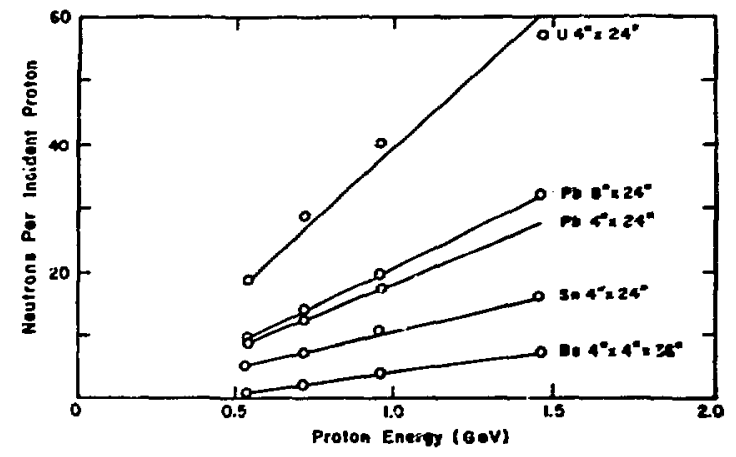

Fig. 2. Production ratio of Iow-energy neutrons per medium-energy proton Incident on var1ous thick targets as a funstion of proton enorgy.

as $25 \mathrm{MeV}$ ), the nucleus can be treated by using experimental free particle cross sections but by constraining the reactions to satisfy the Pauli excluaion pitinctple.

2. Relativistic kinematics are used throughout.

3. The nonzero Fermi distribution of nuclear particles as evidenced by electron scattering data to step-sise approximated by a central sphere and two concentric spherical annull. The neutron-toproton density ratio is assumed constant and equal to the average for the nucleus.

4. The composite momentum distribution for the nucleus is approximated by a 15-MeV Gaussian.

5. The binding energy of the wost loosely bourd nucleon 16 assumed to be $7 \mathrm{MeV}$ for all roglons and all nuclei. The pion potential is assumed equal to the potuntial of the nucleon with which it is interacting.

6. Cherge Independence of the free particle cross sections is assumed.

7. Esergy, conentum, and charge conearvation are requiled.

B. Plon production ta based on the leober codel wt th single or double pion production belng allosed for nucleon-nucleon colliaions and only aingle plon production befag ellowed for a plon-nucleon collielon.

Bffecta not considerad are:

1. The effects of refraction at the nuclenr vurface.

2. Clutering of nucleone.

3. Reduction of the nuclear denatty due to the crecade. 


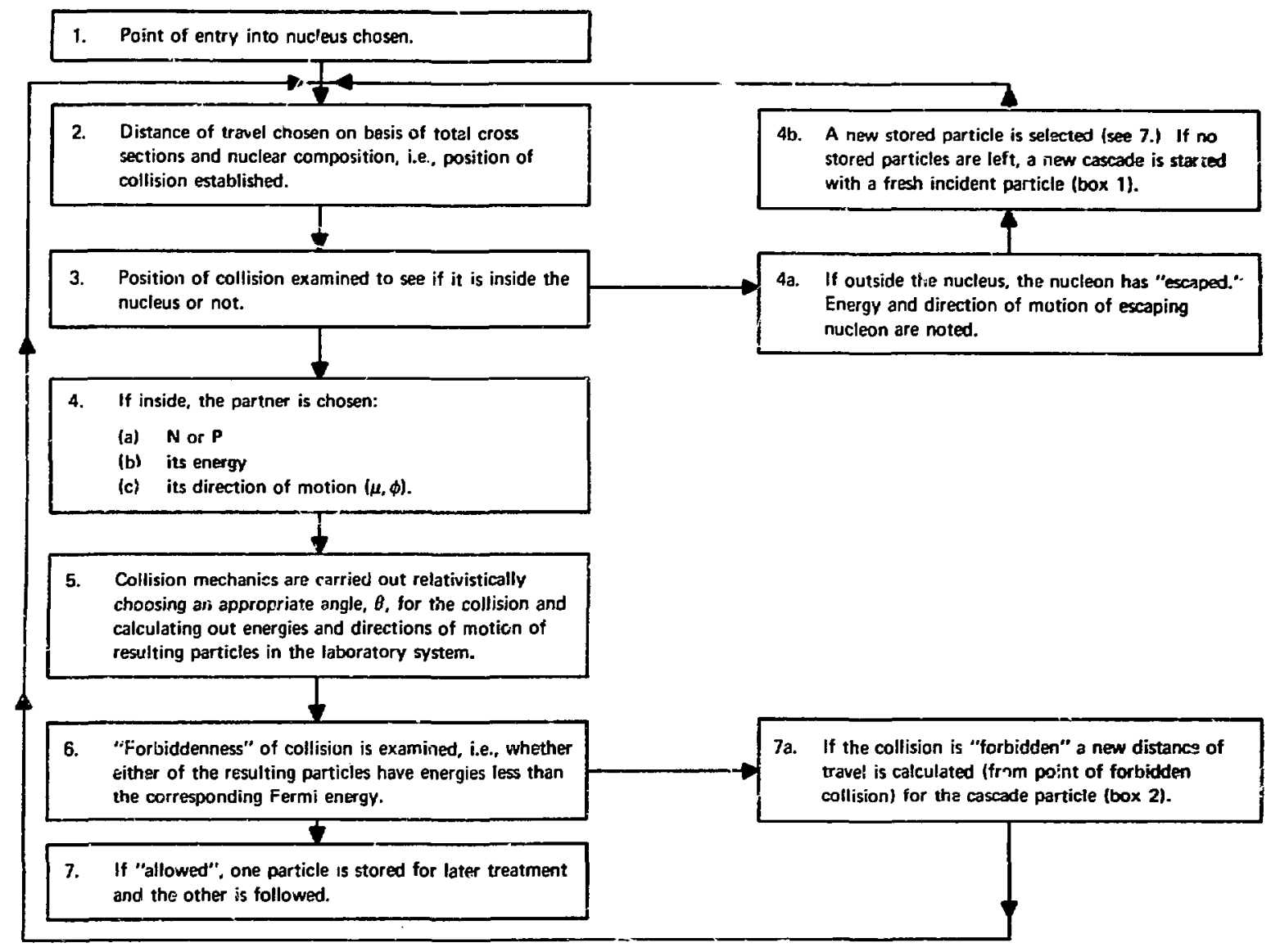

Fig. 3. Block diagram of the course of a Monte Carlo nucleon cascade calculation.

4. Nonspherist ty of nuclel.

5. Spin-correlation effects.

6. Radiative transport that resilt from $\pi^{\circ}$ annthilaticn.

\section{B. Review of the Evaporation Model}

The second step of thts two-step nucleon cascadeevaporation model occurs as the energy of thrs cascade is depleted and particlns can no longer escape. The struck nucleus has an excitation energy $E^{*}=\mathrm{T}_{1}-\mathrm{T}_{0}-$ $\bar{E}_{0}(n-1)$, where $T_{i}$ is the incident particle leinetic energy, $I_{0}$ 1s the sum of kinetic energies of the emtted cascade particles, T. 1e the number of emitted particles, and $E_{0}$ is the assumed binding energy of the most loosely bound nucleon (assumed constent for all pucles.). If the energy of excitation $E^{*}$ is large compared with the lowest excitation levels of the nucleus and the atomlc mass is fatrly high, the problem can be treated statistically as was done by
Welsakopf ${ }^{17}$ He constders the problem of a nucleus A excited to an energy $\mathrm{E}_{\mathrm{A}}^{*}$ enfting a particle $x$ with kinetic energy between $\varepsilon$ and $\varepsilon+d \bar{c}$. After emission the new nucleus $B$ is excited to an energy $\frac{E_{B}^{*}}{B}$ so that $E_{B}^{*}=E_{A}^{*}-b_{o}-\varepsilon$. The probability per unit time $W_{x}(\varepsilon)$ of this occurring can be obtained by thinking of the inverse capture reaction in which the particle goes back into the nucless. By chis reasoning Weisskopf obtaing the protability

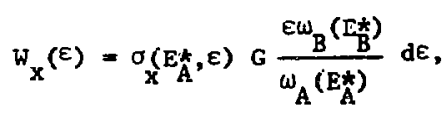

where $\sigma_{x}(E *, \varepsilon)$ is the cross section for the capture of a particle $x$ with a kinetic energy $E$ in a nucleus $B$ to form a nucleus of type A having an excitation $E_{A}^{*} \cdot \omega_{B}\left(E_{B}^{*}\right)$ and $\omega_{A}\left(E_{A}^{*}\right)$ are the level densities in $B$ and $A$ around energles $E_{B}^{*}$ and $E_{A}^{*}$, respectively. $G$ is 
a geometric factor such that $G=\left(2 s_{x}+1\right) m_{x} / \pi^{2} h^{3}$ where $S_{x}$ is the spin of particle $x$ and $m_{x}$ is 1 ts mass.

Monte Carlo techniques were applied to this evaperation approach by Dostrovsky et al. ${ }^{18}$ and more recentiy by Dresner ${ }^{19}$ and Guthrie. ${ }^{20}$ Guthrie's program is contained in the latest version of NMTC, but all three approaches are simflar. The 1dea is to approxdmate the experimentally neasured inverse cross sectlin $\sigma\left(E_{A}^{*}, \varepsilon\right)$ by an emplrical equation ${ }^{18}$ whose parameters are only a fimction of the compound mass $A$ and exission energy $\varepsilon$ for the neutron. For charged particle enission, the cross section is a function of various tabulated quantities including the charge $z$, the charge of the ext+1ng quantity $z_{x}$, nuclear and particle radi, etc. ${ }^{17}$ The level density is essentially that of a degenerate Fermi gas but Includes pairt." energy. ${ }^{18}$ in Guthrie's treatment this is extended to include shell plus pairting energies. The nuclear masses used are those of Mattauch et al., given in tabular form.

The next procedure is to calculate the emlssion probability by integrating Formula 1 over allowable energies for neutrons, protons, deuterons, trltons, hellum-3 nuclef, and alpha particleg. The probabil fty is normalized by dividing each probability by the sum, and the type of particle 13 selected at random with this probability distribution. Similarly, the kinetic energy of the enteced particle is selected at random with a modified laswellian diatribution. If the particile is charged, an effective Coulomb energy is edded. The procedure is repeated for the new nucleus, evaporating more particles untiI it is no longer energetically poseible.

The assimptions in the evaporation model are:

1. That there are many nucleous in the nucieus and that the density of states is high.

2. That the excitation energy is much higher then the lowest levels.

3. That the analytic representations of the Inverse cross sections, level density functions, and Energy distribution functions are correct and that the shell end palring effects are adequate.

The fact that fission and radiative emission cannot be treated is unfortunate. Also most experdmental tests are limfted to medium-welght nuclel.

\section{Experimental Tests of the Nucleon Cascade-}

\section{Evaporation ModeI}

In principle, if the Input data, which in this case are generated by the nucleon cascade-evaporation unodel to a Monte Carlo transport program, are cozrect, correct answers ghould result. There have been numerous checks of the Nucleon Cascade Model. ${ }^{4-14}$ In the most recent revlew, Bertint ${ }^{21}$ crompares hig results wth 39 experlments. Table II attexpts to summerize the agreement between the model and the experiments. Unfortunately, except for the radiochemical expertments, the experiments do little to test the evaporation model; however, Dasirovsky ${ }^{18}$ presents data In its support. From these evidences,

TALE II

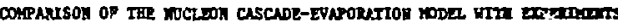

\section{Expexing}

Tonmlastic erose mection for protoos and poucton of conteren ah to

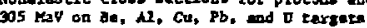
In

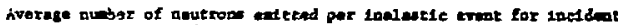

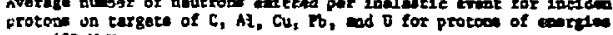
$400 \mathrm{KaV}$

$400 \mathrm{MaV}$
$500 \mathrm{MeV}$
$660 \mathrm{MeV}$

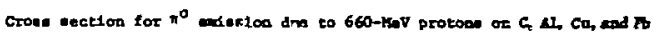

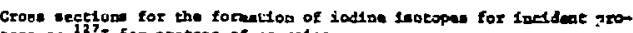
cone on 127 I for protom of meratis

$720 \mathrm{Mar}$

$2000 \mathrm{MaV}$

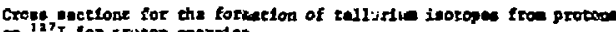
I tor prutor enerples.

2000 หar

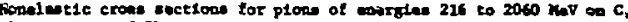
11, Cu, Ru, and p:

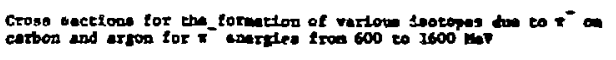

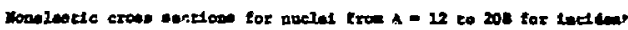
proton anargla

$30 \mathrm{Art}$

$40 \mathrm{mat}$

$\sin _{60}$

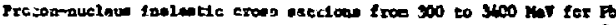

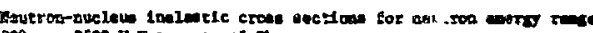
$300-$ to 7500 - Top tersets of 10

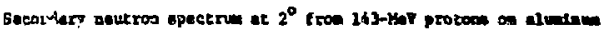

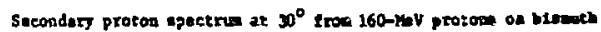
Secondery proton epectron at $30^{\circ}$ from 360-5at protose ou carnos Secondery proton epectrui at $30^{\circ}$ from 450 -kev protom on almane

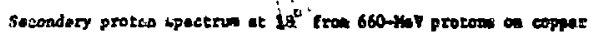
Secondery $r^{+}$apactre at $0^{\circ}$ froe 72 -liop protewe on copper

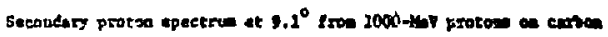

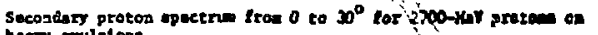
hesty miloge

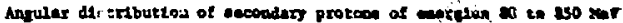

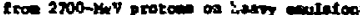

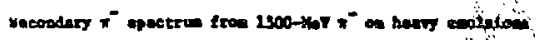

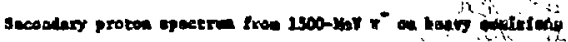

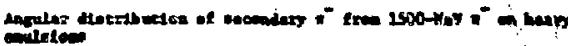


and for 800-HoV protons on heavy metal targets, an estimate would put the accuracy of the model at about 207 .

\section{COMPUTATIOHAL PROCEDLIRE}

The nucleon cascade-evaporation model allows the calculation of nucleon-nucleus, pton-nucleus inter ctlons down to a cutoff energy taken to be 2.5 $\mathrm{MeV}$, but procedures are ueeded for transporting the particles in thick targets and allowing for tonlzatlon energy loss. Procedures are also needed for transporting particles down to thermal energles and for treating fission and gamma production. Figure 4 shows the procedures followed.

\section{A. Nucleon Meson Trangport Code NMTC}

Tnis code, which originated at the Oak Ridge National Laboratory (ORNL), was written in FORTRAN IV for the IBM $360 / 75$ and $360 / 91$ compuce.$i$ and was convarted for use on LASL's CDC 6600 . Th1s code calculates the reactions induced in other nuclet resulting from the neutrons and charged particies generated by nucleon cascade and evaporation from the nucleus struck by the initiel particle. These calculations are performed by Monte Carlo particle transport techntques that differ in some particulers from the isual neutron Monte Carlo transport calculations. These differences are listed.

1. Cross sections are generated internally using the nucleon cascade-evaporation model predictions.

2. The continuous-slowing-down approximation Is applied tic the transport of charged particles.

3. Elastic collisions of protons, neutrons, and plons with all nuclel other than hydrogen are neglected.

4. $\pi^{\circ} ' g$ are essumed to decay in place into two gamma rays. The decay in flight or at rest of charged pions into muons is treated. The capture at rest of $\pi^{-}$'s is treated through the nucleon cascade-evaporacton model. The decay of mons is also treated.

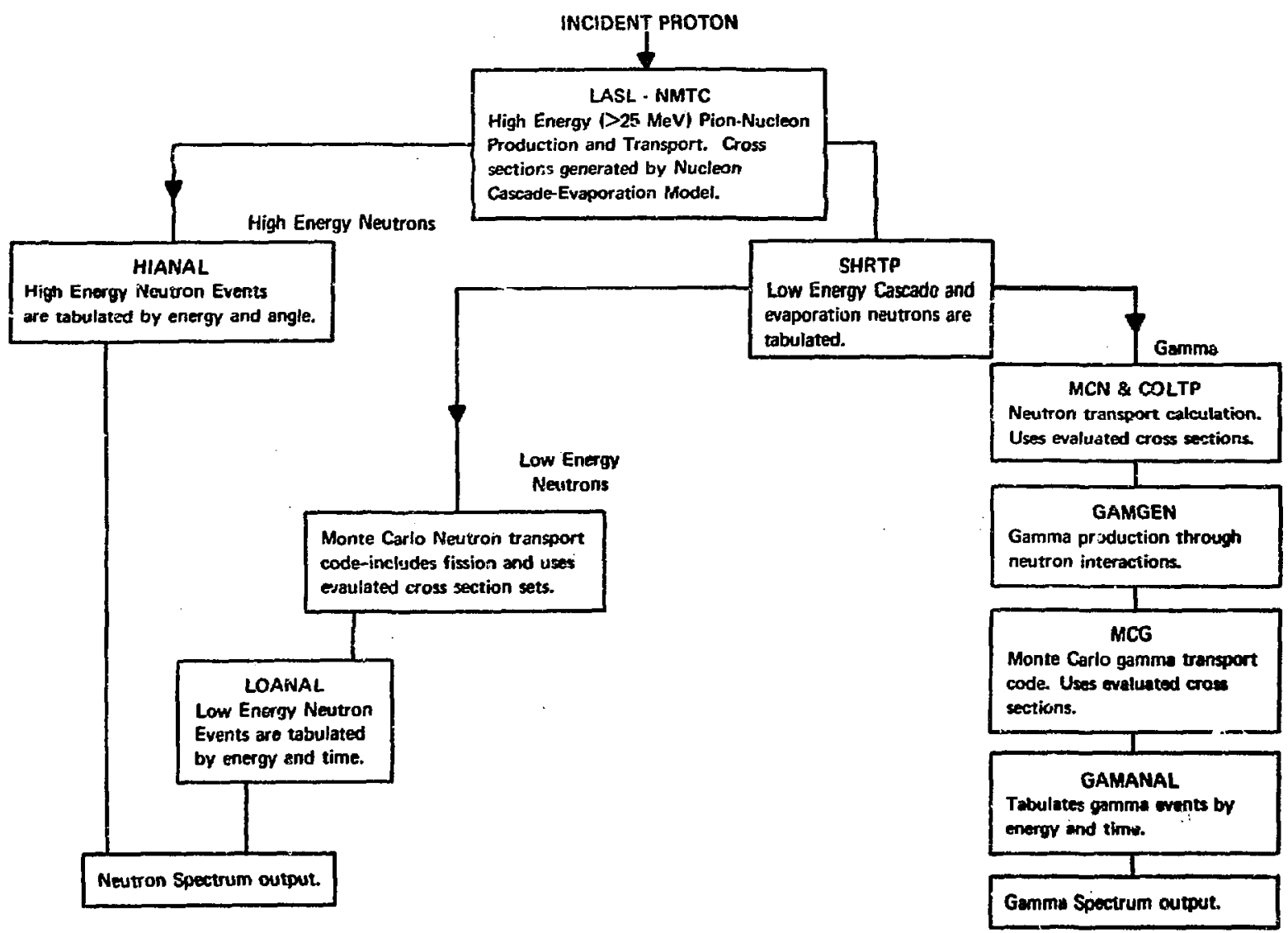

Fig. 4. Block diagram of computational procedures in this report. 
5. NMTC has an upper $11 \mathrm{mit}$ of $2.5 \mathrm{GeV}$ and a lower IImlt 1 mosed by the nucleon cascade-evaporation model of 15 to $50 \mathrm{MeV}$, selectable in the program. In th1s work $25 \mathrm{MeV}$ was used based upon the experficasc of Alamtller et al. (ORNL) ${ }^{3 l}$ and upon our deterndnations that the calculations werf Insensitive to $\pm 10 \mathrm{MeV}$ varlation in the cutoff energy of about $25 \mathrm{MeV}$.

6. The geometry package in the LASL version of SMrC has been modtfied to include caly spheres and cylinders. The low-energy trangport (>25 Mev) in this version is handled by several other programs (FIg. 4) rather than by the $05 R$ (Ref. 22) routine in the ORHL program. With these changer, the program occuples $302500_{8}$ core locations and has a central processor ruming tfme of 0.9 sec per starting proton.

There are two output tapes from NHTC. One tape was used in the ORNL version as the input to 05R for the low-energy trensport and is not used in the LAS $L$ version. The nucleon-plon history tape used in this version contains a record of esch event that occurs in the colliston process. Th1s tape was processed in three different ways (Fig. 4): highenergy neutrons, low-energy neutrons, and gamma rays. E. High-Energy Meutron Spectra

The program HIgh energy ANizifgls (HLANAL) searches the history tape and correlates the neutrong laaving the target with energy above the lowenergy cutoff Into angle and energy bins resulting In numbers of stetistical significance. The aximuthal angle relative to the direction of the irctdent pzoton is divided Into 12 equal solid-angly groups. The energy bins were divided into constant lethargy intervals.

C. Low-Energy Neutron Spectra

1. The history tape is again searched by the program SHRTP (Search TaPe) for two classeb of neutrons. Class I: Those neutrons produced by the nuclear cescade but having energy below the cutnef exergy. They are recorded by position, direction cos1nes, and energy. Class II: Those nutrons produced by evaporation. The two classes ara recorded by position and energy only, because of asaumed 1sotroptc production. They are asserbled on an output tape in autable neutron vource fork.

2. The neutron tranoport 1s calculated by a

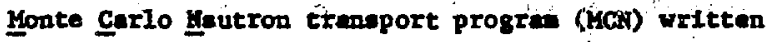

by LASL Group TD-6. ${ }^{23}$ It includes a versatile geometry package, uses optional standard varimce reduction techniques, and treats neutron thermalfzetion by usiag the free-gas model. The code uses pointwise cross sections from several conplletions. Infortunately, the maxtmum energy of these conpliatione Is $14.6 \mathrm{MeV}$; hence cross sections auc be extrapolited up to $2.5 \mathrm{MeV}$. This was done by Schrandt, Grewer, and Beyserer ${ }^{24}$ for ${ }^{230} \mathrm{~J}$ by using nuclear syateintics. Appendix A describes thetr procedure. The output data of MCN Includes currents, fluxes, point datector responses, and other data not applicable to this problen. It also includes a history tape output ined In LOARAL.

3. The Low Energy ANALysis progras (woikit) searches this tape, and correlates the neutrons in Intervale of energy, angle, and tive to obtain nuivbers of statistical significance, and produces an output simflar to HIANAI so that the two outpute nisy be grouped to produce the complete neutron sutput spectrum from source to theinal energles.

D. Gamma-Ray Spectra

The gamma-ray production calculation fo oased on the suggestion of R. G. Alsmiler; Jr;, (ORNi) that most of the gamma rays are produced by interaction of the low-energy neutrons with the target nuclel resulting In Inelastic scattering end cipture with subsequent radiative deexcltation of the nuclet. Therefore, the gamm-ray prodictlon from the nucleon-neson cascade or from particle evaporation is not considered. The rationale for this approdinition Is the $5: 1$ domlnance of evporation neutrong over ail other cascade or evaporation particlep. These peutrons are the primary source for the gen-ray production calculation.

1. The history tape is again eerched by sairip to provide the 10 -energy cascade und fviporyfion neutron source for transport In MG, thich benorates a collision tope. The posttion, enares, twe, onil numbri, and weighi is recorded for ench ervent:

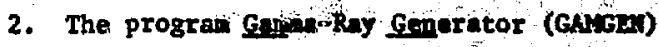
was written by W. G. Preeg (iAsL Group TD-3) to une the collisions to gevarate a gen-ray source band on the ratio of the gama-ray productlon croas sectIon to the total crose section. The enrjent gone rays are randaily selicted from a cumbitive probeblltey tabla. A uer-ielatted I portence function may be ued to affect the gan-ray iultiplicts for 
each event. Multigroup production cross sections from the ENDF/B file may be used. However, for the calculations Involving ${ }^{235} \mathrm{U}$ and ${ }^{238} \mathrm{U}$, the TD-Division data set was elployed.

3. The transport of the gamme rays from GAMGEN Is done by MCG, a general purpose Monte Carlo Gamma transport code written by IASL Group TD-6. The Interaction wechanisms in this code are (1) pair production, (2) Compton scattering, and (3) photoelectric capture. The deposited gamma-ray energy is calculated as is the energy spectrum of the gamma rays transported out of the gystem.

4. The output of MCG is the same as MCN in that events are tabulated on a history tape. These histories are summarized to obtain statistically Bignificant data by. the Gamma-Ray Analys is (GAMANAL) code. Th1s code sumnarizes the gamma-ray output according to energy, angle, and tIme of emisston, similar to LoANal.

E. Alternative Neutron Trausport Calculation

Before leaving the discussion of the calculation procedure for particle production and transport, an alternative approach not used in this report is discusiaed. This approach, used by Bertint, consists of generating differentlal cross sections using the nucleon cascade-evaporation model. In this manner cross sections are generated for Incident neutrons and protons from 25 to $40 \mathrm{MeV}$ and Incident $\pi^{+}$and $\pi^{-}$ from 25 to $300 \mathrm{MeV}$ on nuclel from carbon to uranium. 25,26 This was later extended to cover 500 to $3000 \mathrm{MeV}$ for Inctdent protons and neutrons and 500 to $2500 \mathrm{MeV}$ for incident $\pi^{+}$and $\pi^{-}$mesons on ${ }^{16} 0$, ${ }^{27} \mathrm{Al},{ }^{65} \mathrm{Cu},{ }^{100} \mathrm{Ru}$, and ${ }^{207} \mathrm{~Pb} .{ }^{27}$ These resillts were given an analyc representation by Atsmiler $28-30$ by lesst-squares fitting to a power serles in exting particle edergy. The coefficients for this representation are a function of angle, exting particle type, and incident particle type and energy. The NCDATA program ${ }^{30}$ interpolates between these analytic representetions to give values for all incident energles in the allowable range and all mass. values between 12 and 238. These cross-section data are combined with standard reactor-type cross-section sets and are used in neutron transport-cades in which the continuous slowing down approximation has been added for the transport of charged particles. 31,32

This approsch does the particle transport in one code and hence avolds the joining region at 25
$\mathrm{MeV}$. It would appear to be a faster wethod because the cross sections are not generated in the course of the program, but are retrieved. Hence greater geometric complexity as to shape and materiai can be treated for the same computer usage. At the Los Alumos Sclentific Laboratory, D. R. Harzis, Jr.; D. L. Roeder, R. A. Haarman, R. P. Forrest, Jr., and $H$. I. Israel have collaborated in generating the nucieon-cascade events for the elewents $C, 0$, $\mathrm{Al}, \mathrm{Mo}, \mathrm{Fe}, \mathrm{H}$, and ${ }^{2{ }^{\circ} \mathrm{U}}$ for nucleons and Lons from 25 to $800 \mathrm{MeV}$. To date these data have not been cumplled for use in transport codes but are viswed as the correct approach for complex shieiding and target problems.

\section{v. COMPARISON AND RESULTS}

As was stated in Sec. III.C, if the nucleon cascade-evaporation model is correct, In principle the Monte Carlo transport results should also be correct and there is no reason for Integral compar18ons. Unfurtinately, the calculational procedares are sufficiently complex to warrant integral comparisons. This section presents comparisons with other work both calculational and experimental. In addition, detalls of the spectra from varlous targets, time dependence, spatial profiles, and gama-ray production are presented.

Table III sumarizes the calculations of this report and compares total neutron output fros other ce"culations and experiments. Problem 1 statistically is the most rellable problem of this report. It required about $3 \mathrm{hr}$ CDC 6600 tine just for the NMTC calculation. We planned to zone this problen by radius at 3 and $5 \mathrm{~cm}$ for high-energy neutron production in these sleeves, thus making one problea useful for the calculation of three different cy1Inders. Ninety percent of the neutron production from evaporation occurs in the first $0.75 \mathrm{~cm}$ (PIg. 5); therefore, MMIC calculations for a 15-car-dian by $30-\mathrm{cm}-10 \mathrm{ng}$ target were used for Problem 1, 2 , and 3 (Table III) wth the correct diameter wed in the MCN calculation. Problem 4 is a direct test of this approxdmation in that both NhTs and kot were calculated for the correct geometry. Problew 5 and 6 are studies of the effect of target geometry on the angular neutron spectra. Because the $800-$ $\mathrm{MeV}$ protons have a range of $24.1 \mathrm{~cm}$ in $231 \mathrm{~J}$ ( 40.1 cm in $\mathrm{Pb}$ ), it my seen strange to study targets 
TABLE III

\section{CALCULATION SUMMARY}

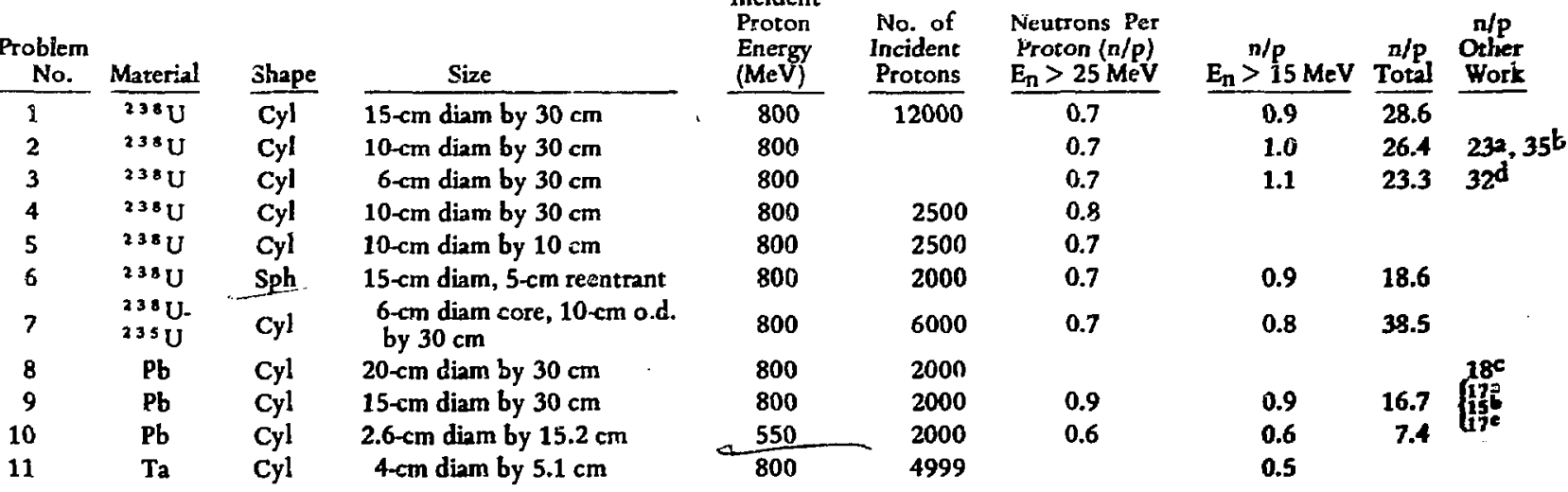

aRef. $33,10-\mathrm{cm}$-diam by $60 \mathrm{~cm}$ target, number is total neutron captures in $1.8 \mathrm{~m}$ cube of water, linear interpolation to $800 \mathrm{MeV}$ Monte Carlo calculation.

bRef. 3,10.2-cm-diam by $61 \mathrm{~cm}$ target foil activation in 6-ft cube of water, linear interpolation to 800 MeV-experiment.

cSame as b except $20.4-\mathrm{cm}$-diam by $61 \mathrm{~cm}$ target.

dRef. 34, 5-cm-diam by $40-\mathrm{cm}$ target, linear interpolation to $800 \mathrm{MeV}$ - Monte Carlo calculation.

eSame as d except 10 -cm-diam by 60 -cm target.

shorter than the incident particle range. Figure 5 111ustrates that the neutron production 18 dropping faster than exponentially toward the end of the Length $\mathrm{cm}$

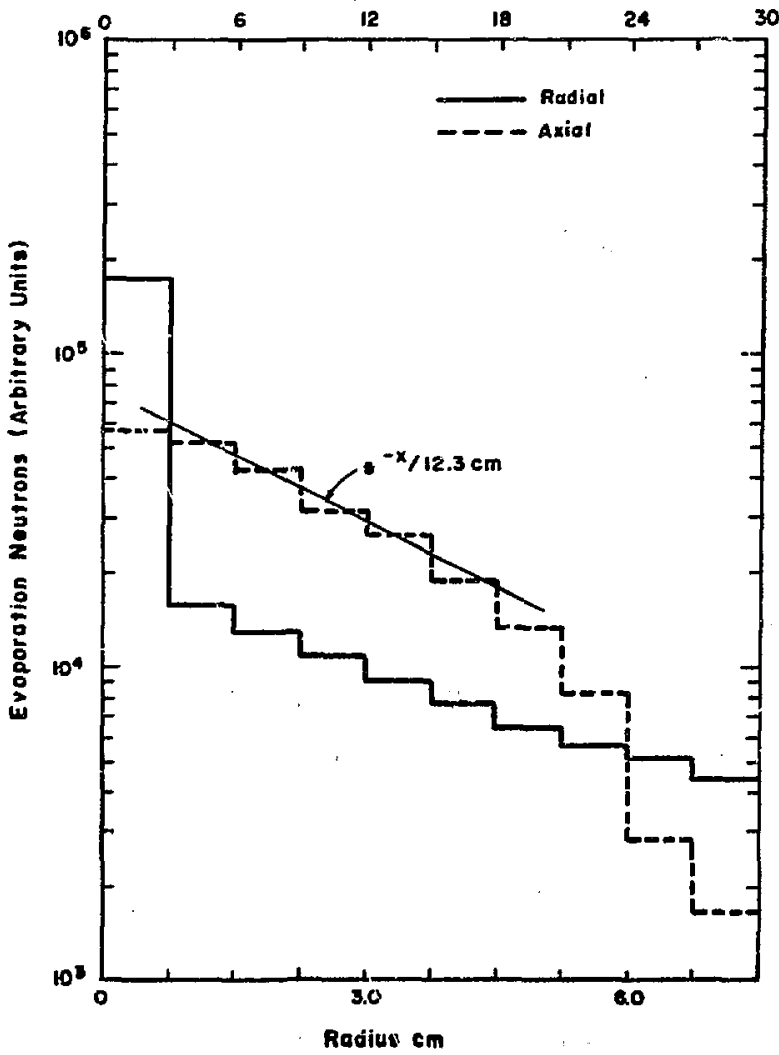

F18. 5. Radial and axial distribution of the production of evaporation neutrons in $=7.5-$ cm-radiu, 30 -co-long $23 \mathrm{~V}_{\mathrm{V}}$ target with $800-$ MeV protons incident on exle. proton range. An eye fit curve to that portion of the axial distribution that is approximately exonential gives an e-folding of $12.3 \mathrm{cos}$. Plgure $i$ shows the rapid drop of neutron production with anergy, which is another approsch to this problew. If proton energy below $300 \mathrm{MeV}$ Is nompoductive, then, from range-energy curves, $17 \mathrm{co}$ of ${ }^{230} \mathrm{~V}$ w11 degrade the $300-\mathrm{HeV}$ protons to $300 \mathrm{MeV}$. All of this is consistent with $15 \mathrm{~cm}$ of ${ }^{23} \mathrm{~d}$ belng a "most efficient" lergth of target although a bean dine would be needed for the exiting protons.

Problews 7 through 11 explore the effoct of different waterial on the aeutron spectre with a view to spectrum talloring of the targets. Proble 10 models the target for the Colubla kevis synchrotron. Date for this faclliti ludicated atto of neutrons/incident proton $(n / p)$ of 16 . These caleuLations predict this ratio to be 7.4 .

Table III (right two coluna) Indtcaces that the $\mathrm{n} / \mathrm{p}$ ratios are in close agremint wth the work of ORNL. Th1s result is not eurprtating becene these culculation we the relatively unchanged ourINTC program. Calculating the low-eners tranpoort with MCN is different ind wes different croes-taction sets so that the end agreemnt is gratifyins. Surprisingly, the Monte Carlo prediction of islton knd Fraser ${ }^{34}$ give on $n / p$ ratio 273 higher then the ORNL work. The Canadian-U.S. themalisution-follactivacion experteant results ${ }^{3}$ are aloo higher them these by $25 x$. 


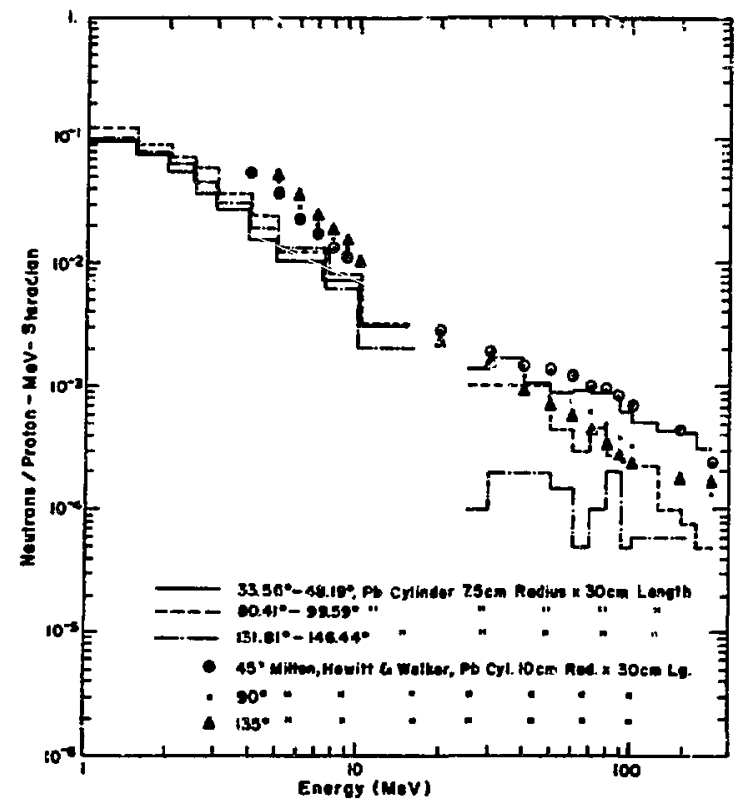

F1g. 6. Neutron spectra comparisons between these calculations and the experiment of Milton, Hewitt, and Walkar (Ref. 36). The leazd target was $20-\mathrm{cm}$ diam by $30-\mathrm{cm}$ long. The Incldent proton energy was $1000 \mathrm{MeV}$.

F1gure 6 is a comparison of the results of Problen 9 wh the neutrou time-of-flight experfment performed by Fraser, Hewit $t$, and Walker ${ }^{35}$ on the B1rmingham Synchrotron. Comparisons of the data aroind 10 MeV place these experiments 20 to $4,0 \%$ higher than our calculations. From 30 to $150 \mathrm{MeV}$ the agreement 18 good for the $45^{\circ}$ spectrum, falr at $90^{\circ}$, and foor at $135^{\circ}$. In the jointing regton between MMTC sind MCN at $25 \mathrm{MeV}$, the statistics are very poor and the data are outted.

Recent1y, Veeser et al. ${ }^{36}$ measured the angular neutron spectrum from a 15-cm-diam by $30-\mathrm{cm}-10 \mathrm{ng}$ ${ }^{29} \mathrm{U}$ target bombarded by $750-\mathrm{MeV}$ protons from the Lewrence Berkeley Laboratory's 184-1n. synchrocyclotron. Several detection techniques were used ${ }^{37}$ and the agreenent below $10 \mathrm{MeV}$ (FIga. 7 and 8) is very good. The data above $10 \mathrm{MeV}$ are consistently higher than these calculations but are st111 subject to revision. However, the small number of nevtrons in this regicn that are above $10 \mathrm{MeV}$ cannot alone account for the dfiscrepancies in the $\mathrm{n} / \mathrm{p}$ racto. In sumary, the $-25 \%$ discrepancy in the $n / p$ ratio for

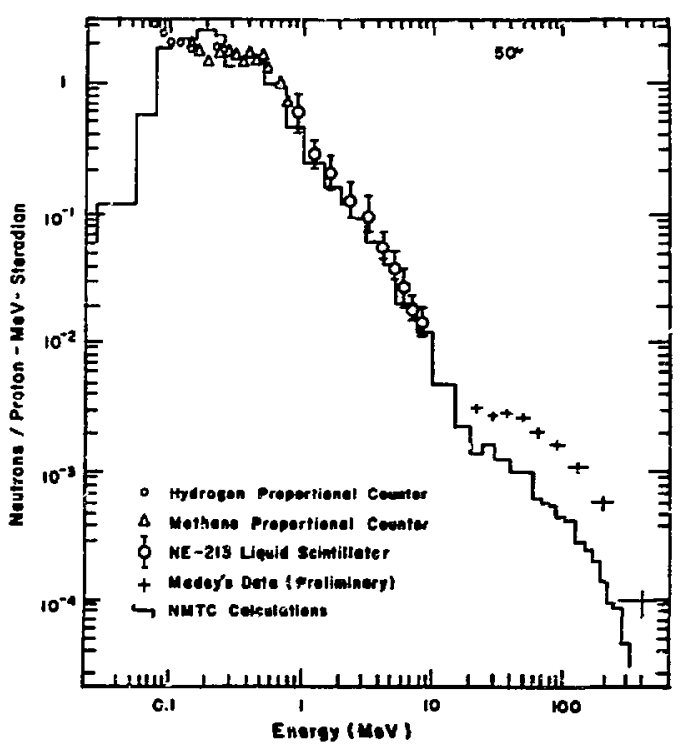

F1g. 7. Neutron spectra comparisons between these calculations and the expextment of Veeser et al. (Ref. 35). The ${ }^{238} \mathrm{~V}$ target 15-cm diam by $30-\mathrm{cm}$ long was measured at $50^{\circ}$. The Incident proton ezergy was $750 \mathrm{KeV}$.

${ }^{238} \mathrm{U}$ as calculated by MMTC and that weasured ${ }^{3}$ and calculated ${ }^{34}$ is not understood.

Table IV on target heating does not provide a test of our calculations. This wes not an orfiginal objective of this work and cannot $n \mathrm{~W}$ be recovered

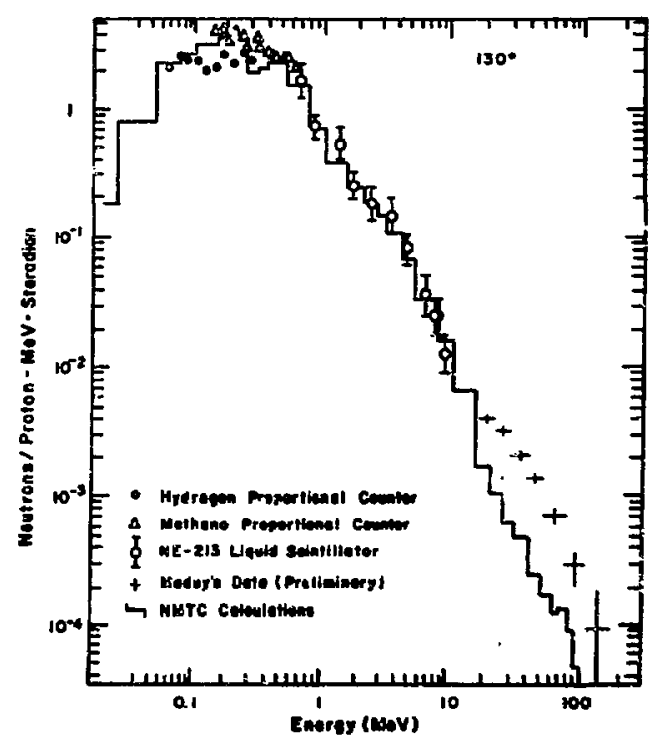

F18. 8. Neutron spactra comprisons betwen these celculations and the expertinent of Veaser et al. (Rof. 35). The ${ }^{2} \mathrm{U}$ target 15-ea dien by $30-\mathrm{cn}$ lons was neasured at $130^{\circ}$. The Incident proton energy wa $750 \mathrm{MeV}$. 
THU: IV

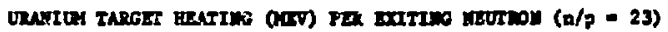

\begin{tabular}{|c|c|c|c|}
\hline & Lef. $33^{\circ}$ & ent. $3^{b}$ & Inse Heist \\
\hline $\begin{array}{l}\text { Ionization loas for charged } \\
\text { partieles bove } 25 \mathrm{HaV} \\
\text { excluding becas }\end{array}$ & 18.3 & & \\
\hline $\begin{array}{l}\text { Huclenr weteation due to } \\
\text { reaction bove } 25 \text { ing }\end{array}$ & 0.36 & & \\
\hline rinatic eneres of $\pi^{\circ}$ wenon & 0.39 & & \\
\hline 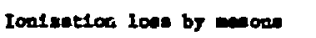 & 0.02 & & \\
\hline $\begin{array}{l}\text { Deaction du tu particles } \\
\text { balo } 25 \mathrm{MV}\end{array}$ & 37.2 & & $16^{c}$ \\
\hline Totel bant: in texget & 56.3 & 77 & \\
\hline
\end{tabular}

900-xiap incident proton meres.

bIntexpolated to $000 \mathrm{MaV}$.

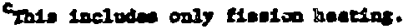

from the calculations. Data on Elssion heating are. presented, however. It is surprising that the ORHL work should disagree with expertment by as much as 377. Agatn, this is only true of ${ }^{299} \mathrm{U}$, a fact that moy be significant.

This completes the neutron production conparisons with prevlcus work. Flgure 9 presents results for Problem 1, Table III, below $25 \mathrm{MeV}$. An unexpected result of this work 1s the "softnesg" of the

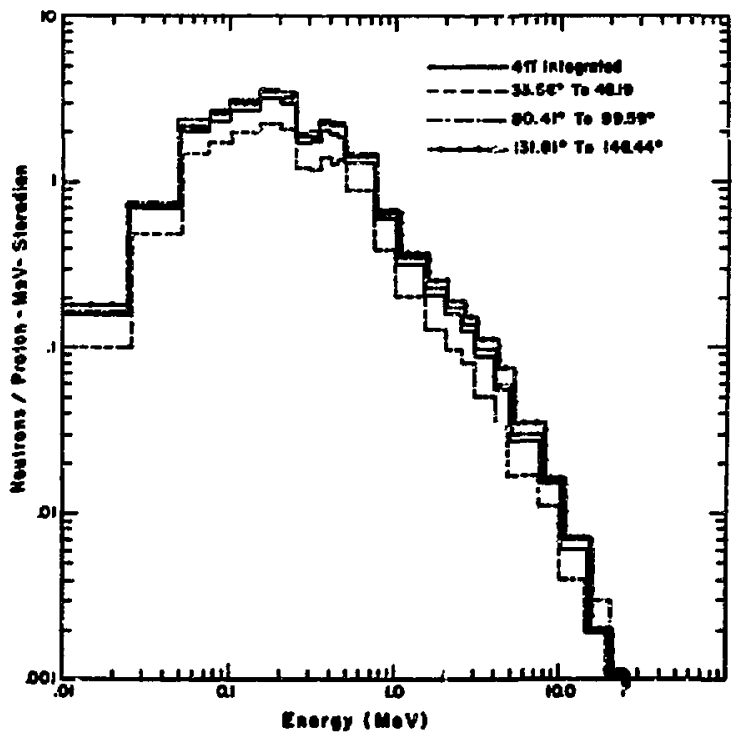

F18. 9. Celculated neutron spectra befow. $25 \mathrm{kgV}$ for 15-cin-dian, 30-cm-10as $281 \mathrm{~V}$ cylinder with 800-2ive protons incident on ade.

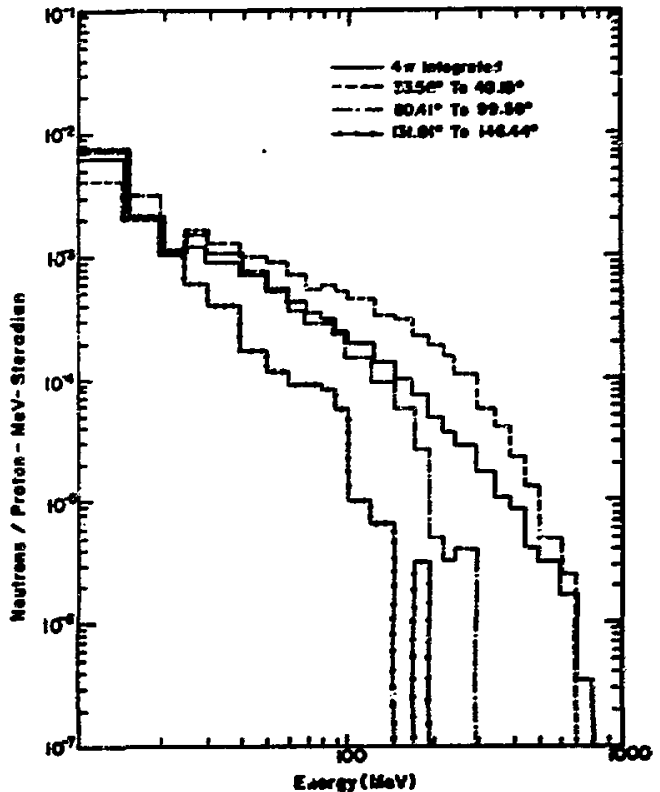

F1g. 10. Calculated seutron spectra bove $10 \mathrm{kgV}$

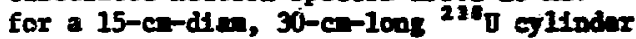
with 800-tiev proton incident on wexs.

spectrum, as shown for the large targeta, rowultins from neutron elastic and aultiple froduction reactions. He expected the spectrun to be of inlar to a evaporation spectrux, but this vas not the caen. Figure 10 shows the neutron spectra bove $10 \mathrm{Hap}$ for this ste problem. Appendix B contaln tebular resulte for all the celculetions bove $25 \mathrm{kiv.}$. Ficure 11 sugarlixa Figa 9 and 10 by presenting the percentage nutron output as a function of the upper 11nit of integration.

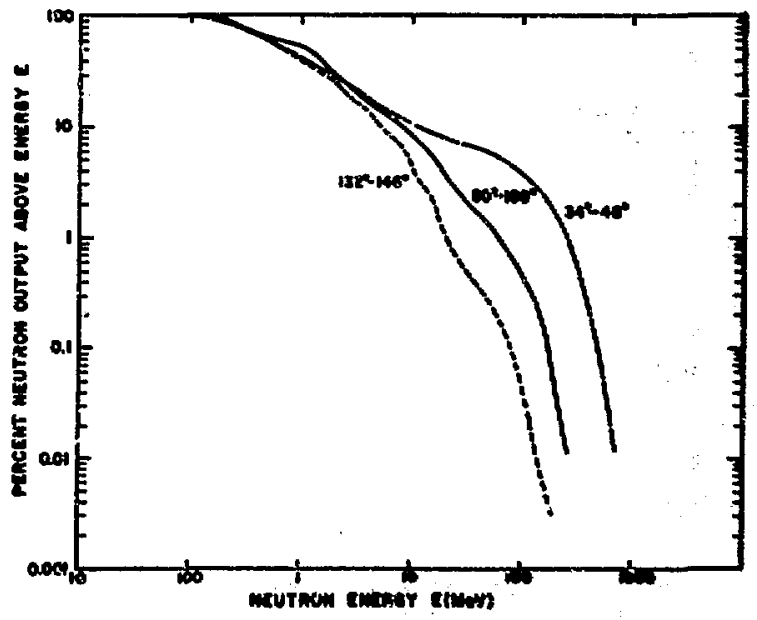

F1. 11. Fexeentage nutrod oulsut bore a neveren enerey $\mathrm{I}$ as a function of that and. 


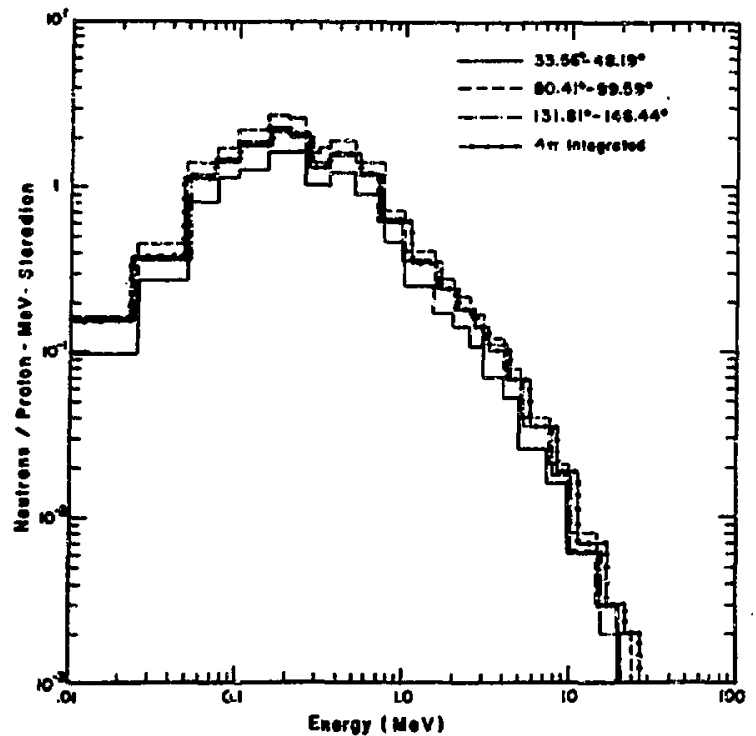

19. 12. Calculated teutron spectra below $25 \mathrm{MeV}$ by zoning wethod for a $10-\mathrm{cm}-\mathrm{di} \mathrm{am}, 30-\mathrm{cm}-10 \mathrm{ng}$ $23{ }^{2} \mathrm{U}$ cylinder with $800-\mathrm{MeV}$ protons incident on axds.

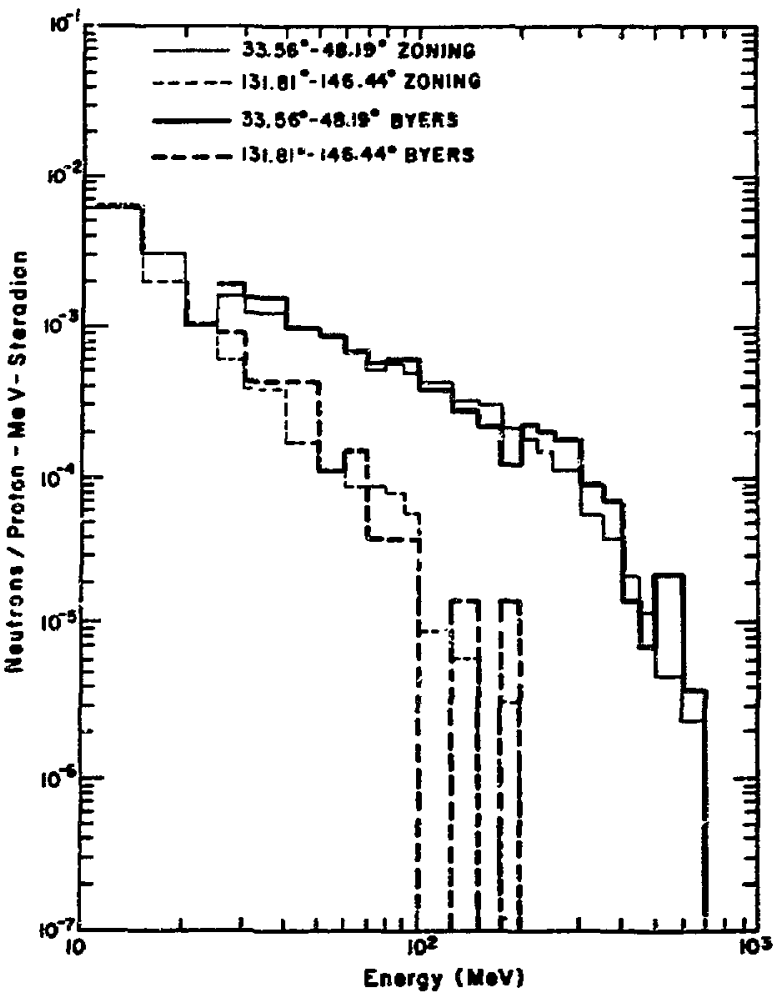

F1g. 13. Celculated neutron spectra sbove $10 \mathrm{KeV}$ by zoning wethod for 10-ce-dia, 30-ce-lons ${ }^{20} \mathrm{v}$ cylinder with 800-keV protons inc1dent on axis. Aiso includei for comartson 18 Byers' calculation for actual geomatry.

F1gure 12 showe the angular vartation in nav tron opactra below $25 \mathrm{KeV}$ for Probles 2; the 10-codia by $30-\mathrm{cm}$ long ${ }^{230} \mathrm{U}$ target vas calculated by the zoning technique. Figure 13 showe the spectra sbove $10 \mathrm{HeV}$, which is the eane as show in FIg. 10 but is repeated to show conparieons with Byers" calculation performed for the correct geonetry.

Flgure 14 presente data for Problen 3 with the 6-ci-dian by $30-\mathrm{cm}-100 \mathrm{~g}{ }^{290} \mathrm{~d}$ targat agein done by zoning. Bacause the spectra above $10 \mathrm{MaV}$ are Identical (by this athod) to thoe shown In Mge. 10 or 13. thay are not repented.

PIgure 15 show, in a polkr plot, the angular distribution of the high-energ neutrose. Because evaporation and fiesion-produced noutron sre essuned leotropic, a low-enery plot is not presented.

Figures 16 and 17 compare the offocts of target hape on the angular diatribution. The cciparieon 18 ande For Problen 1, the 15-cr-dien by 30-cr-loas 


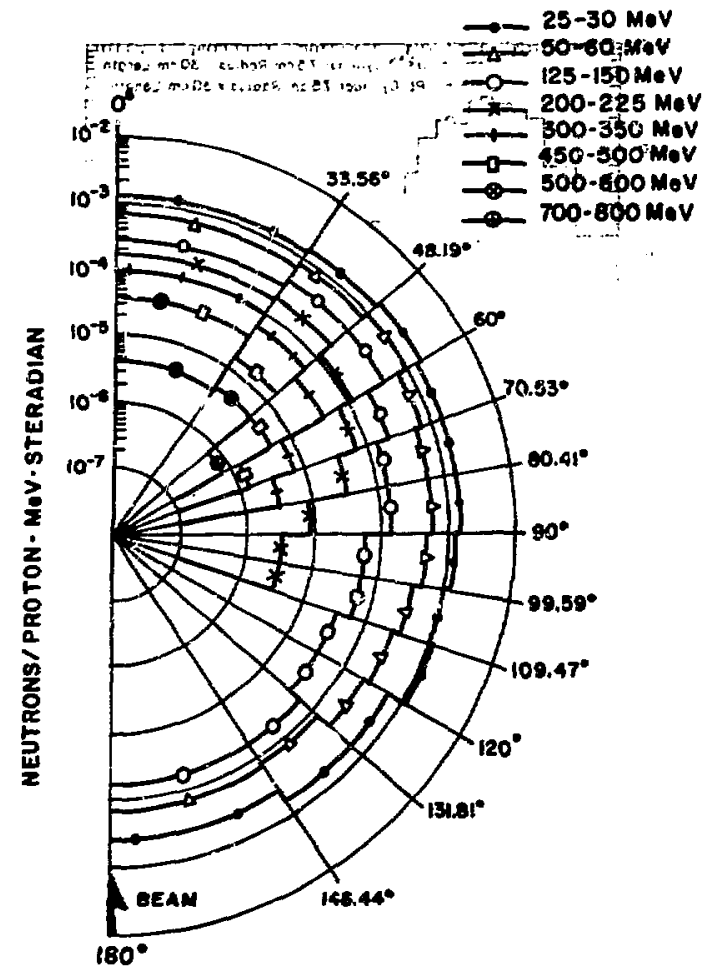

P18. 15. Colculated angular neutron spectrum for 15-co-dian, 30-cu-long ${ }^{230}$ o cylinder with 800-MeV protons Inctdent on axis.

290 $\mathrm{U}$ cylinder; Problen 5, the 10--in-diem by 10-carlong $220 \mathrm{U}$ cylinder; and Problea 6, a 15-cardian ${ }^{230} \mathrm{U}$ solld sphere. As would be expected from F1g. 5 , the geometry is raelly estoblished by the bean and is not strongly Influenced by the shape of the targat. F1gure 18 showe dranatically the prosase contributing to the 0.2-HaV epectral maximu. The evaporation neutron opectre are essentially the sam in both lead and ${ }^{23} \mathrm{~V}$, but the exping neutron epectru fron $2 \%$ is conelderably wodffled by $(n, 2 n)$ and (n,n'r) procesese that have a mach higher threahold In 1ead.

FIgure 19 compares the $4 \pi$ apectre from ${ }^{230} \mathrm{O}$ and lead cylindert 15-ce dian by 30-aw 1ong. In the regton bure $10 \mathrm{KrV}$, there 1e very little difference between the aterials, but very large differences extot at low energles dwe to $(n, 20)$ and $(n, f)$ reaccloas.

Figure 20 presente rasults for Problen 11, a 4co-dian by 5.1-co-10ns tantalua cylinder with 800KV protow Inctdent. This prólen was done prelietnary to the axpariment of veeser et $a 1 .^{36}$ This

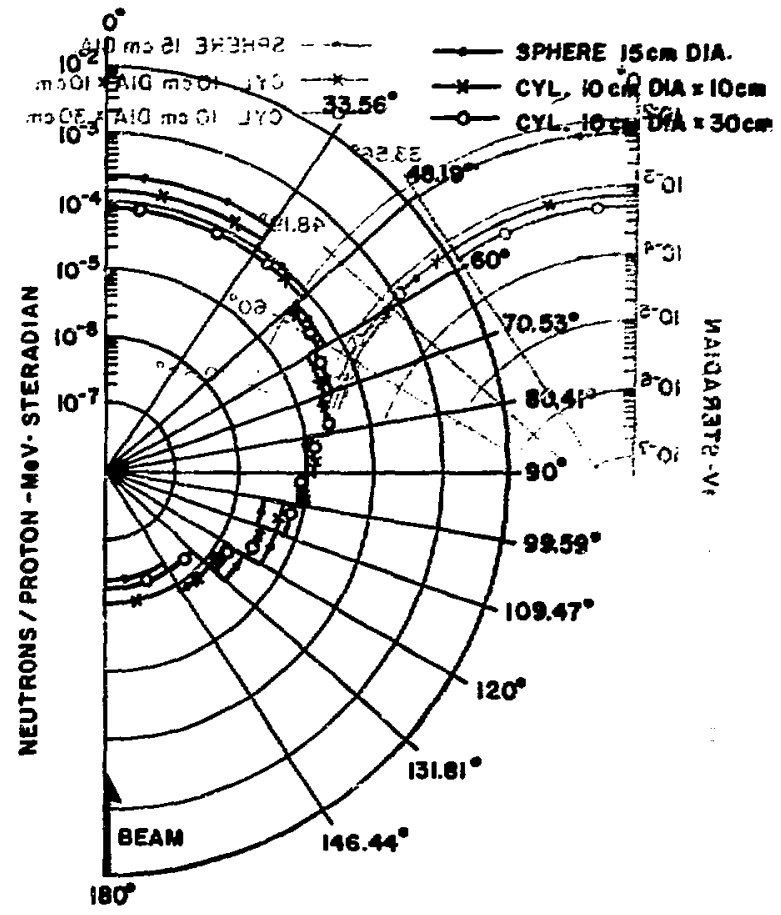

F1g. 16. Compartson of the calculated engulnr nowtron spectre 800 to $100 \mathrm{keV}$ for 15 -co-dies,

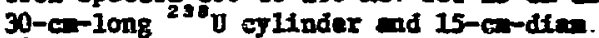
"190 solid sphere with 800-kis protons incident on axis.

target was in a bean IIne ot the Berkeley eyclotron and vas constdered as poustble source of neviroin to checle out detectors.

PIgure 21 ahow the results from Problem 3 and 7 that represent an atterpt both to harden the spectru and to incresse the nautron output by wing

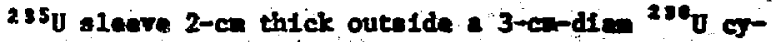
lindrical core. Both renulte are achievid but at tine expease of ciderton tive. Frure 22 bhom the $4 \pi$ tiwendepondent neutrom apectre for the $230 \mathrm{~J} \mathrm{cl}-$ Inder and F18. 23 shore the apectra for the $23 \mathrm{U}^{230} \mathrm{U}$ composite target. The nubber of neutrons in tha later time groupe to Increased, w well whe theng span, thu enkins the compoite target nore difficult to we for neutron tien-of-flicht exporiniate.

Figure 24 preante the tine-depandant noutrea opectra from a 15-ca-dian by 30-ce-lon $110 \mathrm{t}$ carget for a few enors croupe.

Itwee date wy be eye-fitted to give the nowt

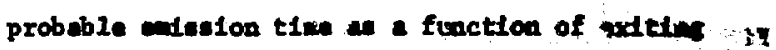
neutron saers

$t=3.5$ neec/ $\sin ($ tiv) 


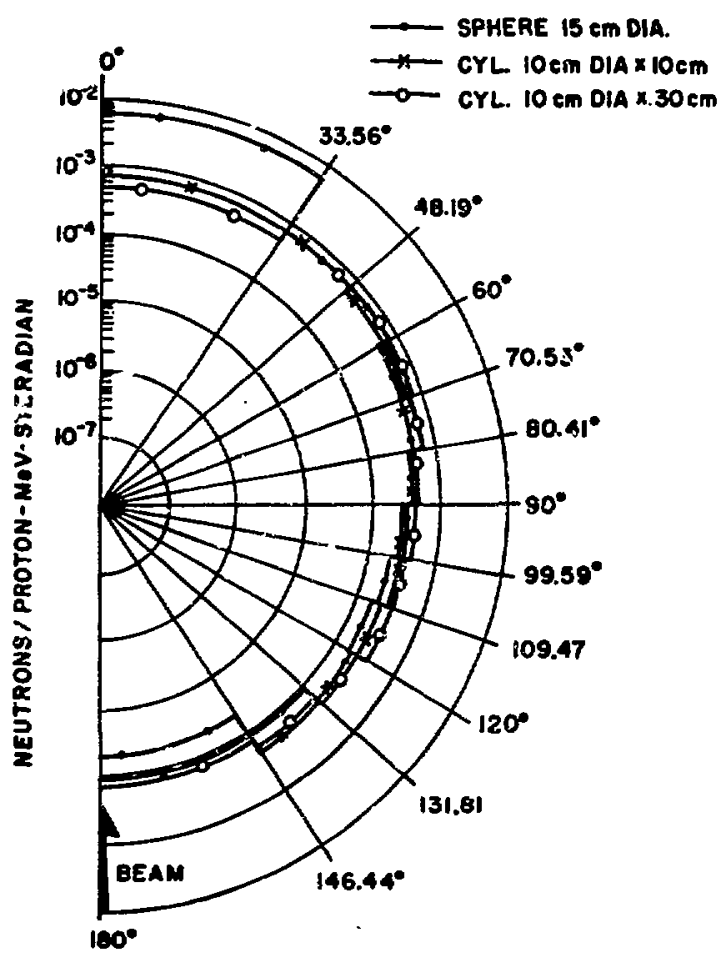

F1g. 17. Comprison of the calculated angular neutron spectra 100 to $25 \mathrm{MaV}$ for 15-crr-diam, 30-c-long ${ }^{238} \mathrm{U}$ cylinder and 15-cu-diam $2{ }^{\circ} \mathrm{U}$ solid sphere with 800-MeV protons incident on exds.

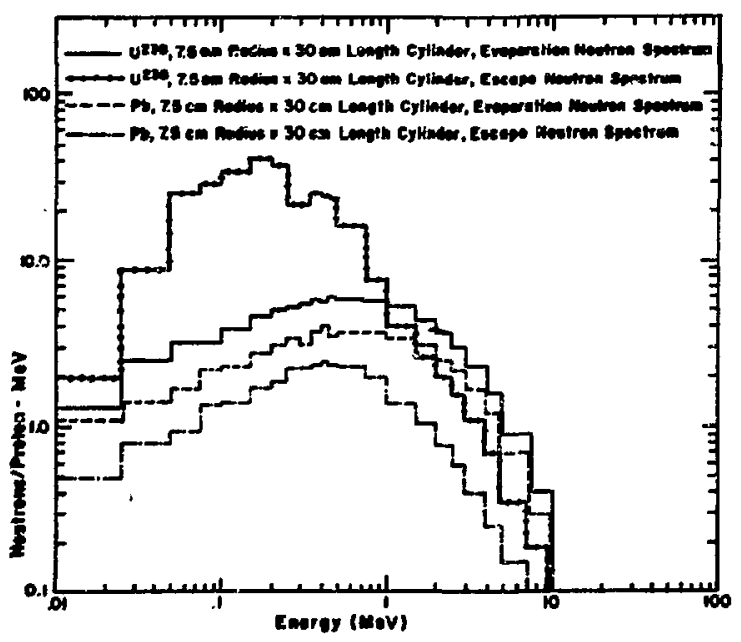

FIg. 18. Comparieon of neutron evaporation and eacape spectra below $10 \mathrm{MeV}$ for ${ }^{23 \mathrm{H}} \mathrm{U}$ and $\mathrm{Pb}$ cylinders 15-ce dien, 30-cm long with $800-$ HoV proton Incident on axds.

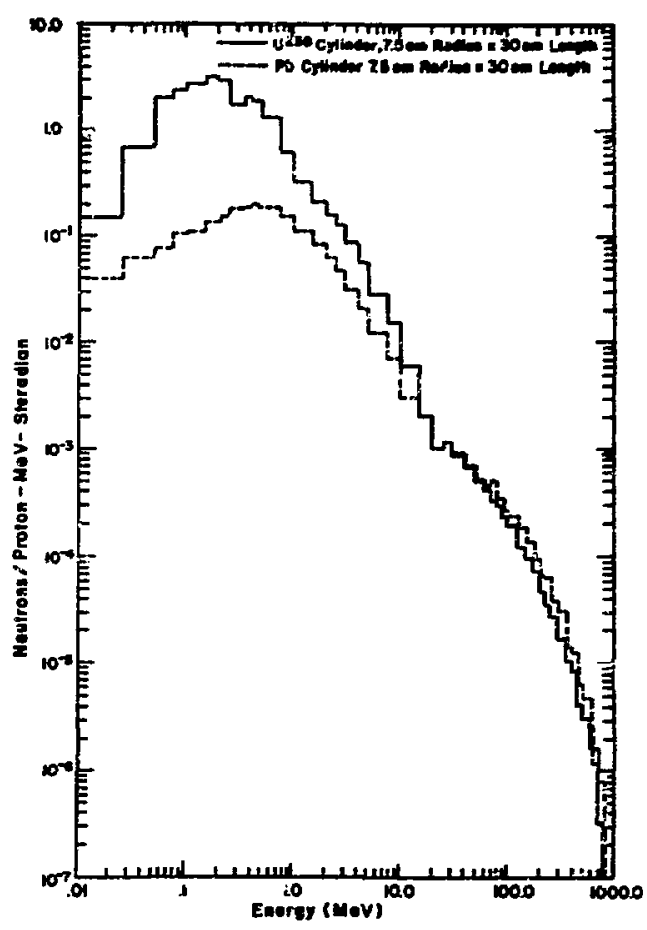

F1g. 19. Comparison of $4 \pi$ neutron apectra for ${ }^{238} \mathrm{U}$ and $\mathrm{Pb}$ cylinders 15-cie dias, 30-co long with $800-\mathrm{MeV}$ protons incident on axis.

and the tiae diaperaion of the exiseton talan hers. as the full vidth at $1 /$ e of the andrum value. This gives

$$
\Delta t=5.2 \mathrm{nsec} / \mathrm{E}^{0.73} \text { (Hev). }
$$

The fact that the mean entasion tine shifte inversely with the velocity of the exiting neutron is to be expected because the target nnifesta cone aspects of a "slowing-down tine" spectronter. If the target were large enough, "velocity focussing" would be antfest.

Uaing the usual relationohip for enersy resolution in neutron tige-of-flight and substitutins $E q$. (3), the frectional energy resolution for a fitht diatence $l$ is given as

$$
\frac{d E}{E}=\frac{0.144}{l(n) E^{1.23}}
$$

For 1-kov neutrons and $100-\mathrm{f}$ flght dietence, the energy resolution ahould be sout $0.14 \%$ (epetial uncertainty to not considered). 

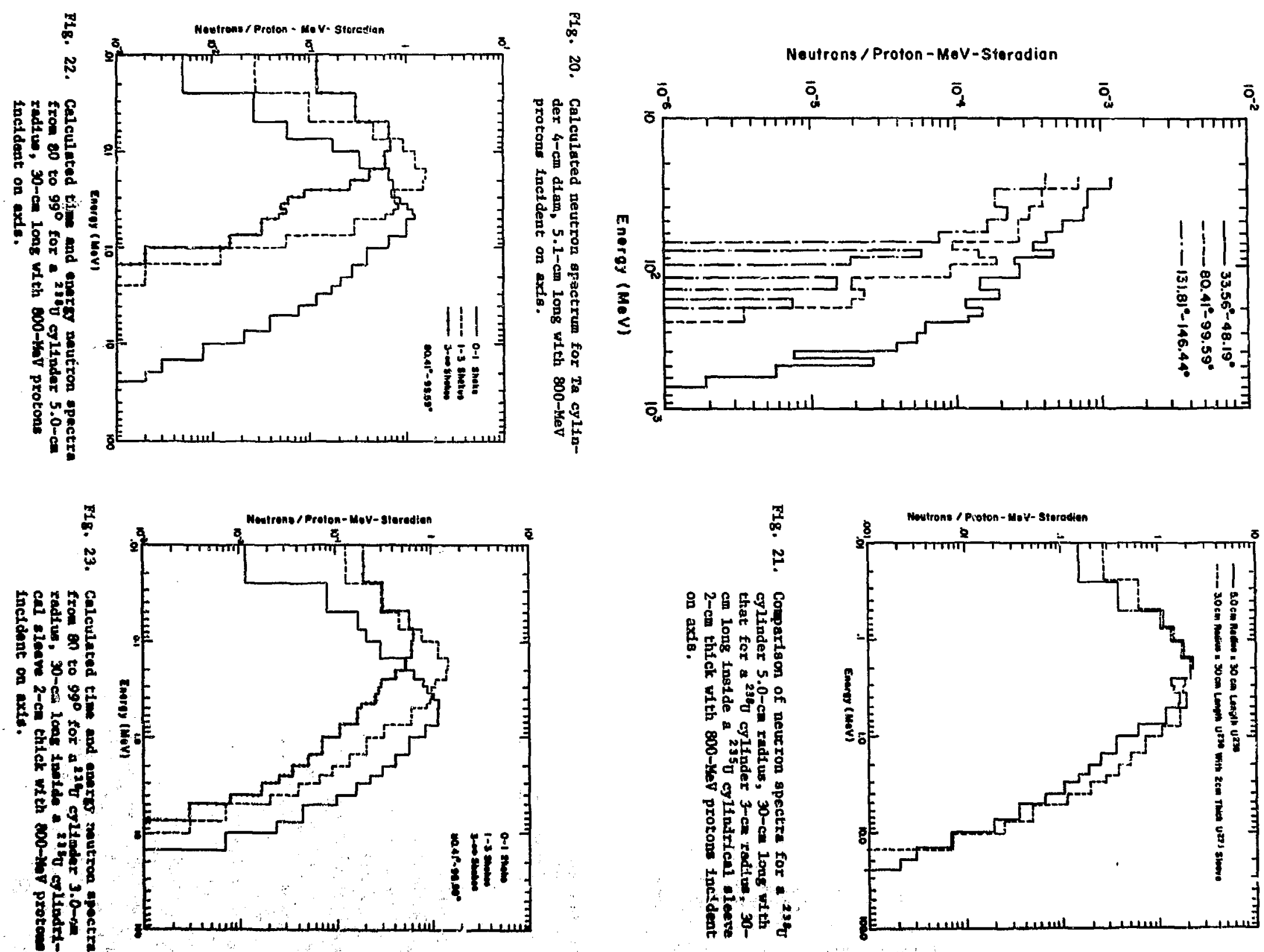


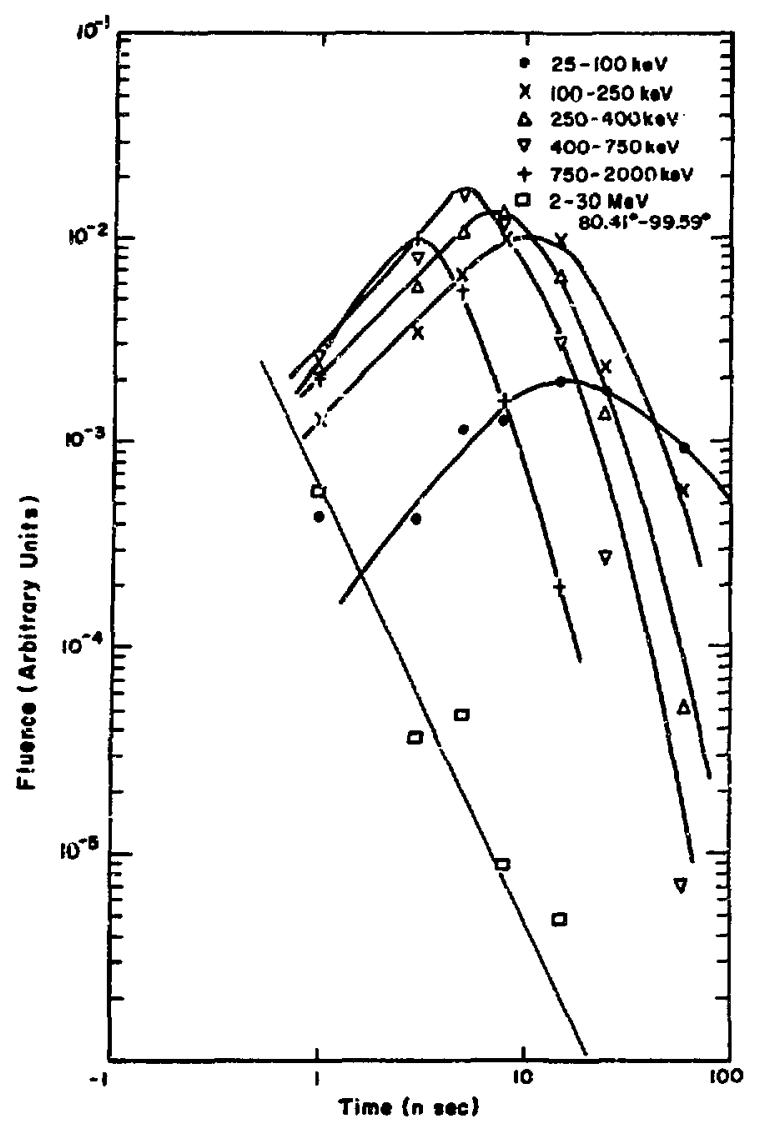

F1g. 24. Time dependent $90^{\circ}$ neutron spectra for several energy,groups from a 7.5-cn-radius, $30-\mathrm{con}-1$ long $2{ }^{3} \mathrm{U}$ target with 800 -MeV protons Incident on axis.

F1gure 25 shows the distribution of the last colligions the neutrons expertarice before leaving the target. If 1 is 18 assumed that the reastions are 1sotropic, then this represents the spatial distribution of a diffuse source. These results show that the last collistons tend to occur at the outer boundary in spite of the fact that the source is concen" trated along the beam line (F1g. 5). These results would Indicate that for experimerts requiring high luninosity, the diameter of the targets should be as small as posatble.

F1gure 26 presents the garma-ray escape spectrum for the 15-corrdiam by 30-cm-long 23 "U target as a function of angle. This shows considerable photon absorption in the forward direction due to taxiset waterial in this direction. The results would be

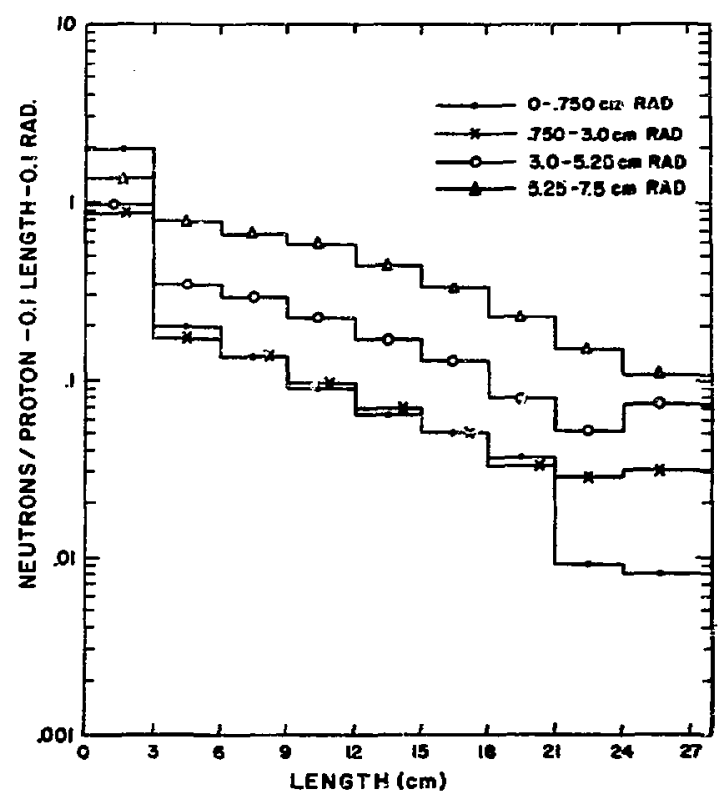

F1g. 25. Axlal and radial distribution of lest colIlsions in a ${ }^{238} \mathrm{~d}$ target 15 - $\mathrm{cm}$ dfan, 30cm long with 800-MeV protons incident on axts.

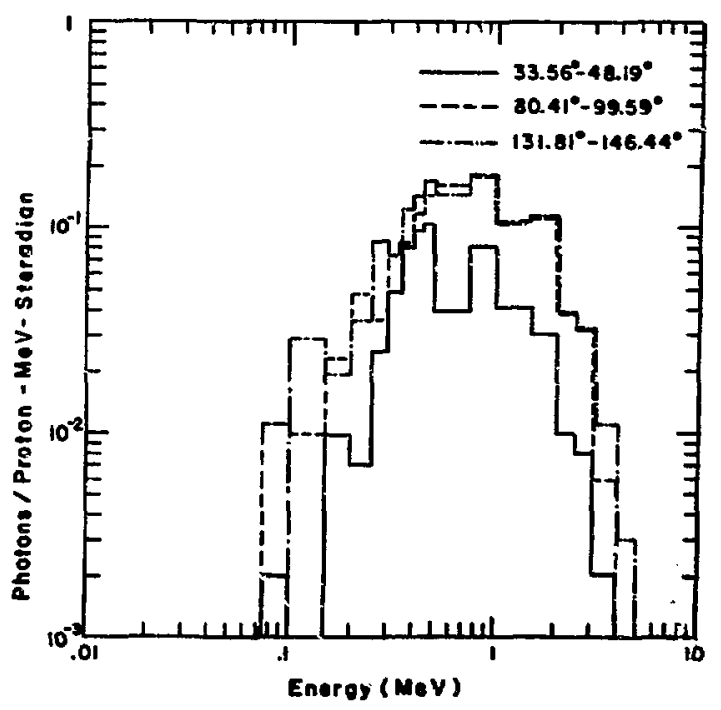

F1g. 26. Calculated angular ginne- ray endesion spectrui for $2^{23} \mathrm{U}$ cy 11nder $5.0 \mathrm{-cm}$ radius 30-ca long with 800-isv protons inctdant on axis. 


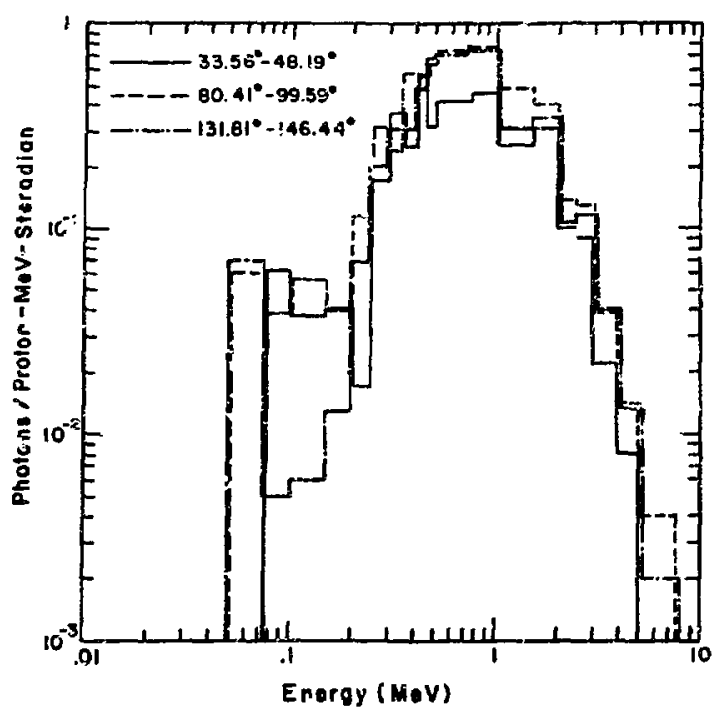

F1g. 27. Galculated angular ganma-ray emtagion spectra fur a ${ }^{23}{ }_{\mathrm{U}}$ cylinder, 3.0-cil radius, $30-c r r$ long lastde a ${ }^{235} \mathrm{~J}$ cyilindrtcal sleeve 2-cm thick with $800-M \in V$ protons 10 clcent on axis.

considerably diffarent for the shorter targets of Problems 5 and 6 . In these thick uranium targets the ganma absorptior 18 such that for 35 photons produced, only 1 escapes.

Flgure 27 shows the same thing for the composite taxget of Problem 7. Now there 1s considerable gamma-ray production on the aurface of tha terget and the angular effect 18 not as pronounced. For every seven gamma rays produced, one escapes. Thus the composite carget improved the $\mathrm{n} / \mathrm{p}$ ratio by $45 \mathrm{z}$, but increased the gemma-ray production by five times and resulted 1n poorer time emlseion characteristics.

Table $V$ is presented for general information to show the relotive abundence of particles produced by 800-MeV proton bonbardment of a 10-cm-diam by 30-cmlong ${ }^{230} \mathrm{U}$ target (Prob1cm 4, Table III). Maay of these particles never leave the target.

VI. COMPARISON (IF THE ( $p, x n)$ SOURCE WITH THE $\{e, \gamma, x n)$ SOURCE

For the reasuns stated in Sec. II, medium-energy protong are not comnonly used as an MeV neutron sourca. However, its potential for this purpose has been desonstrated ia the prevlous section of this report. Bacaue the neutron spectrum ind application are ofinflar to the thick terget $(0, Y, \times n)$
TABLE V

RELATIVE ABINDANCES OR PAPTICLLES

IN THE NUCLEDN-MESOT CASCADE

(from Problen 4; Table III)

\begin{tabular}{lr}
\multicolumn{1}{c}{ Particle } & lumbe: \\
\hline Incldent protons & 2500 \\
Above cutoff escape protons & 89 \\
Below cutoff escape protons & 1281 \\
Above cucoff escape neutrons & 2114 \\
Below cutoff escape ne-trons & 2528 \\
$\pi^{+}$mesons & 31 \\
$\pi^{-}$mesons & 14 \\
$\pi^{\circ}$ mesoms & 25 \\
Evapcration protons & 2551 \\
Evaporation neutrons & 49031 \\
Evaporation tlphas & 634 \\
Evaporation deuterons & 278 \\
Evaporation tritons & 632
\end{tabular}

8pectrum of neutrong produced by high-powerad wicrowave electron linear accelerators, a couparison is presented in Table $\mathrm{VI}$. The edvantages (except for luninosity) appear to favor the use of nediumenergi proton boubardment of heavy metal targets over electron boubardiment. However, these comarisons are on a per fncldent partiele basis and, until recentiy, the high-powerad mcrowave linacs have been vastiy superfior in peak or everage currents to proton accelerators. A compartson of the relative strengths of two expming of these accelerators w111 be deferred unt1 a discussion of the relative warlts of the production mechantsus is completed.

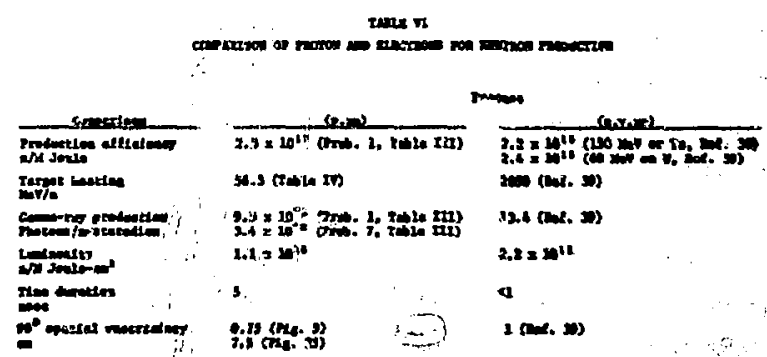




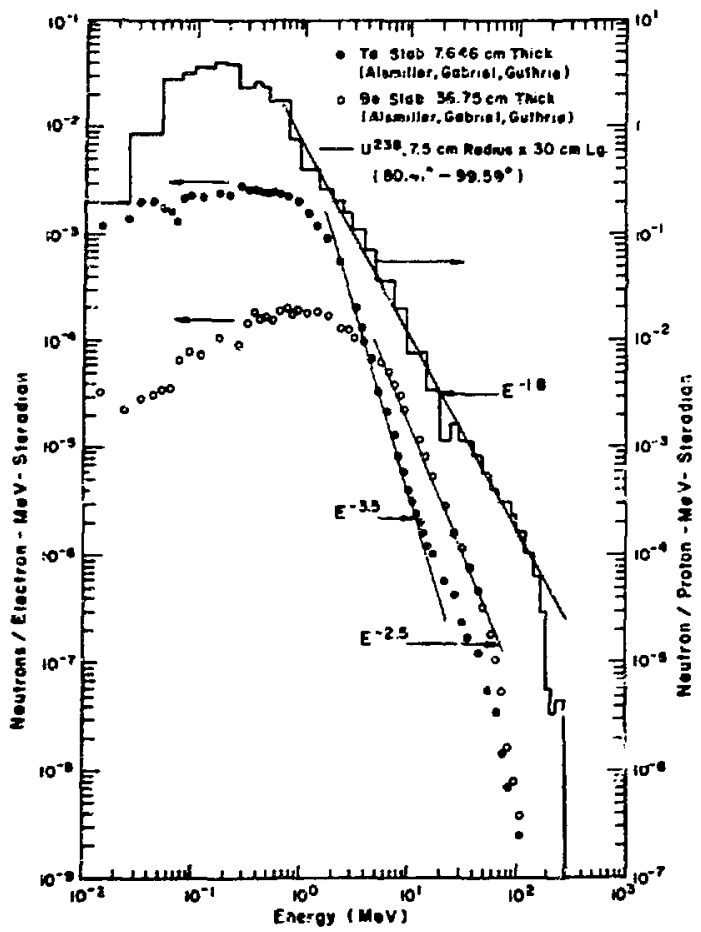

Fig. 28. Comparison of calculated $90^{\circ}$ neutron spectra between $15-\mathrm{cm}-\mathrm{dIam}, 30-\mathrm{cm}-10 \mathrm{ng} 230 \mathrm{U}$ c) linder with $800-\mathrm{MeV}$ protons incident on axds with $2 \pi$ spectra from $7.645-\mathrm{cm} \mathrm{Ta}$ and 36. 75-cm Be slabs with 150-MeV electrons perpendicularly iactdent (from Ref. 40).

F1gure 28 pregents a comparison of the $90^{\circ}$ neutron spectrum from a 15-cm-dian by 30 -cin long ${ }^{238} \mathrm{U}$ cylinder with $800-\mathrm{MeV}$ protons incident on axds with the $2 \pi$ neutron production from $150-\mathrm{MeV}$ electron bombardment of $7.646-\mathrm{cm}$ tantalum and $36.75-\mathrm{cm}$ beryllium slabs. 40 For the $U\left(p_{8} x n\right)$ process from 1 to $100 \mathrm{MeV}$, the spectrum 18 approximately $\mathrm{E}^{-1.83}$; for $B e(e, \gamma, x n)$ from 5 to $50 \mathrm{MeV}$, the spectrum is approsimately $E^{-2,4 B}$; for $\mathrm{Ta}(e, y, x n)$ frow 5 to $60 \mathrm{MeV}$, the spectrum is approximately $E^{-3.40}$. Thus, the $(p, x n)$ process is clearly superior for neutron production in the I to $100 \mathrm{MeV}$ range. Iable VI shows a factor of 100 advantage in total neutron production over electrons on a per incident particle basis, whereas the target heating per neutron 19 only $1 / 50$ of that for electrons.

The gamme-ray production per neutron is 1400 times greater by the $\left(e, \gamma, x_{n}\right)$ process than by the $(p, x n)$ process for the target of Problem 1 , and 400 timeg more for the composite ${ }^{233} \mathrm{U}-{ }^{230} \mathrm{U}$ target of Problem $\therefore$

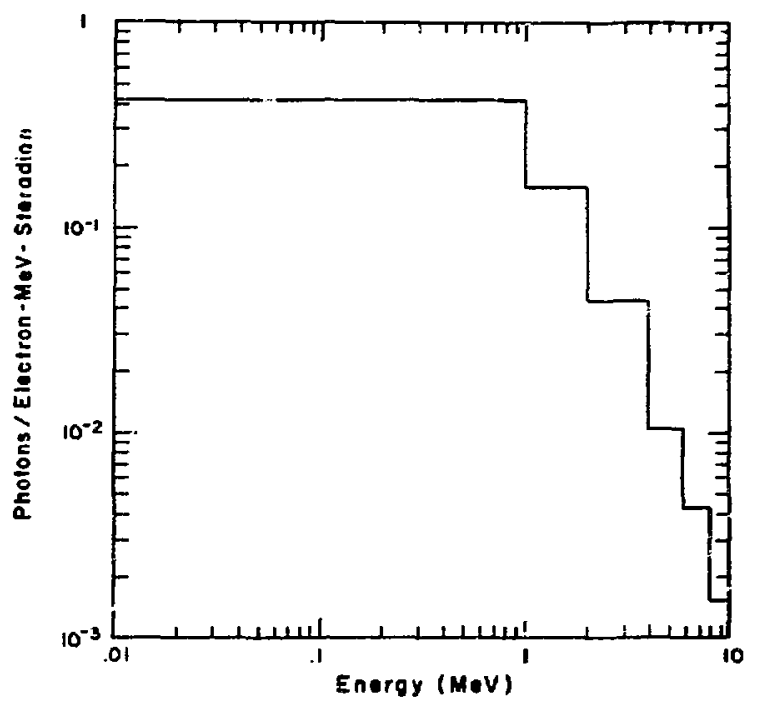

F1g. 29. Calculated $90^{\circ}$ gama-ray emission spectra from 1-cm-iadius, 7.646-cm-long Ta cyllnder, 150-MeV eleccrons Incident on axis (from Ref, 38).

Figure 29, taken from the work of Alsmiller and Moran, 38 shows the photon spectrum at $90^{\circ}$ to the beam line tor the $150-\mathrm{MeV}$ electron incident on the axts of a tantalum cylinder $1-\mathrm{cm}$ radius by $7.646-\mathrm{cm}$ long. Figure 29 should be compared with Figs. 26 and 27. The similarity is noticeable although tine electror. produced spectrum goes to higher gama-ray energles. No doubt the thickness of the uranium targets is a large factor in this suppression. 41

To suppress the gamma flash, numerous techniques are employed. It is not unusual to reduce the neutron fluence by a factor of 10 for the Instrumentation to recover shortly after the pulse. Perhaps the wost sophisticated approach is that of Macklir, 42 who uses a "halo" moderator 6-1n. o.d. by 2-in. 1.d. with the $(e, Y, x n)$ target in the center and with a shadow bar of copper preventing direct viewing of the target. This moderator has a solid angle of about 38\%. For this thickness of wederator the probab111ty of an interaction is $60 z$ so that about $1 / 5$ of the neutron production is usable. This figure is only approxdmate because neutrons cannot scatter $90^{\circ}$ off hydrogen in the laboratory systen.

If neutrons are being pioduced for we at energles from $100 \mathrm{keV}$ to $20 \mathrm{KeV}$, the woderator scatter technique of gana flash suppression 1 s not sutteble, 


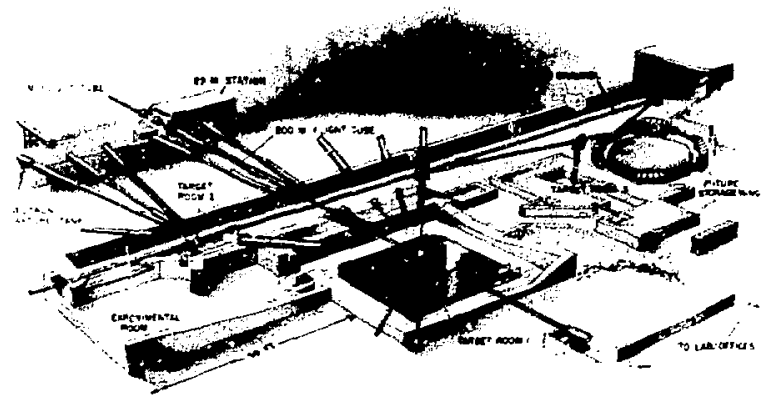

F1g. 30. Simplified drawing of the WNR facllity for time-shared usage of the LAMPF proton and H beams.

and filters and reduction of intensity must be used. We expect that direct viewing of the target will be possible with the $(p, x n)$ process because of the small and suppressed gama flash. Whether or not this can be done for all experiments we must await experimental confirmation.

Iuminosity is an area $1 \mathrm{n}$ which the $(p, x n)$ reaction is infertor to the $(e, \gamma, n)$, but if the moderator scatter technique is used here there is not much difference. Arother area of inferiority is the time duration of the burst. The electron targets are faster and the opatial uncertainty is less because of the smaller size.

The advantages of the $(p, x n)$ reaction have been apprectated for some time but have been explotied only for low-energy physics at the Columbia Untversity Nevls aynchrocyclotron. However, the world's most powerful proton source, LAMPF, will soon be operational with an energy about optimum for neutron production by the $U(p, x n)$ reaction. To use a portion of this beam, a time-sharing scheme has been devised. This profect is called the Weapons Neutron Research (WNR) facility. ${ }^{43}$ Figure 30 is a simplified drawing of the facility excluding the beam-sharling apparatus. A primary consideration in the design of WNR was the angular neutron spectrum shown in FIg. 15. Most experimental areas were designed to use neutrons enitted at $90^{\circ}$ or $135^{\circ}$, althougn some use is made of the forward high-energy spectrum. Target Room 2, (Fig. 30) designed to take a full $25 \mathrm{~kW}$ of beam power, has a trench in which remotely selected targets r1se from on integral shield and nay be located at varlous pleces, depending upon experimental ruquirements.
Target Room I is Intended for low-power oparation to minimize wall activation that would interfere with personnel access. The grating flcor and the large size of the room are to minimize room return radiation. The general arrangement is to have the highest radiation areas down stream. Target Room I is Intentionally located between Target Room 2 and the lab-office area to provide extra shielding.

Comparison of this proposed research facillty using the LAMPF beam to generate neutrong through the $(p, x n)$ reaction and other outstanding facillties w113. now be mada. The proton beam from LAMPF is des1gne: to be $17 \mathrm{~mA}$ when averaged over the $202 \mathrm{MHz}$ fine structura of 0.2 nsec bunches. It is plamed, by simply chopping and time-sharing the beam, to have pulses of duration from 20 nsec to $2 \mu s e c$ avatlsble, 120 pulses per sec (pps). To achieve 5 nsec or less pulse duration, subharmonic bunching of the beam is required which could also result in substantial increases in the neutron production rate.

A later step in the development of WNR is a storage ring to serve as a beam concentrator. In the high duty mode we hope to infect a 7,5-usec proton pulse Into the betatron space of the storage ring. With a ring period of $290 \mathrm{nsec}, 25$ turns would be stored to be compressed by radiofrequency bunching into five bunches of 5-nsec duration, each having a peak current of $300 \mathrm{~mA}$. The bunches would be extracted unfformly at a 600 pps rate. The lowduty mode would ut $111 \mathrm{ze}$ charge exchange injection whereby the $1.7 \mathrm{~mA},-\mathrm{H}$ beam designed for LAYPF would be multiturn injected for $2 \times 10^{4}$ turns in the storage ring. This would require $0.1 \mathrm{sec}$, then after bunching a pulse of 100 A protons of $100 \mathrm{nsec}$ duration would be avaliable but at a very $10 \mathrm{w}$ ducy (one every $10 \mathrm{mf}$ ). It must be emphasized that such a storage ring is a state-of-the-art development and accomplishment is by no means certafn. Table VII summarizes these remarks and makes comparteon. with the Oak Ridge ORELA, which has been In operation for several years and is the best example of high intensity achleved through stored electromagnetic energy. 44 Also compared is the Columbia Untversity Nevis synchrocyclotron thet, efter coapletion of the 1mproved program, will be apiral-ridge fixed-field alternating gradient aynchrocyclotron. 45

The problem of garma flash is considared crudely in itew 6 and 7 of Table VII, but in the 


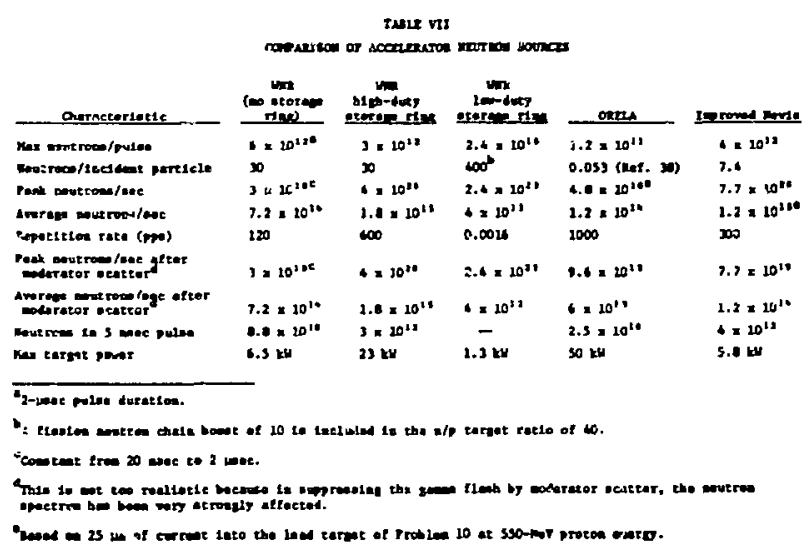

last analysis such compartsons become meaningless and the experirental usage dictates the techniques. As an example, if the faclitty la used for neutron experiments requiring energies between 1 and $20 \mathrm{MeV}$, the moderator scat:ter technique for gamma-flash suppression is unsuitable because of 1ts extremely strong degradation of neutrons of these energies.

\section{CONCLUSIONS}

This report summarlizes a series of calculations on varlous aspects of neutron production by mediumenergy proton bombardment of heavy metal targets.
We belleve that any further calculations should involve group cross sections in a single Monte Carlo calculation without the arbitrary break where this report joins two calculational methods. He tope that this would permit more expeditious problem solution and at the gane time 1nclude detalls of cooling channels in the target design.

\section{ACKNOWLEDGMENTS}

For two years many people have made signiflcant contributions to this report. Special credt is given to Harvey I. Israel who coded MmTC for the Los Alamos Sclentific Laboratory computer center and also to Don $H$. Byers who carrled out several of the problems and wrote the code SHRTP. Lynn R. Veeser also carrled out several problens and we are grateful for permission to include his results and experimental measurements. W. G. Preeg deserves special credit for help on the gamna-ray production problem, and Lewls E. Agnew, Jr., performed some of the early work on these calculations. R. G. Alsmiller, Jr., (ORNL) deserves credtt for his help and interest in the course of this work. John R. Beyster (Sclence Applications, Inc.) devised the cross-section extrapolation technique of Appendix A. Finally, Arthur Hemmendinger and Robert G. Shreffler supported tinis work to its conclusion.

\section{APPENDIX A}

CROSS-SECTION EXTRAPOLATION TECHNIQUES USED BY SCHRANDT, CRAMER, AND BEYSTER

In the Schrandt-Cramer-Beyscer studies of the target problem, 24 the cross sections for ${ }^{230} \mathrm{U}$ between $14.6 \mathrm{MeV}$ and $25 \mathrm{MeV}$ were obtalned by the following procedures.

1. The total and fission experimental cross sections from the Lawrence L1vermore Laboratory (LLL) Howerton compllation for neutron energies of 17, 20, 23,26 , and $30 \mathrm{MeV}$ were used.

2. The average number of neutrons per figsion (v) was calculated using the formula of Hunter et al. ${ }^{46} \bar{v}=2.38+0.149 \mathrm{E}$ (MeV).

3. Cross sectlons for the $(n, 2 n)$ and $(n, 3 n)$ reactions were nupplied by Leona Srewart (LASL Group TD-4) up to about $20 \mathrm{MeV}$. A smooth falloff of the $(n, 3 n)$ reaction was assumed, and for this reason data in the LLL compilation were not uaed.

4. The thresholds for the $(n, 4 n)$ and $(n, 5 n)$ reactions were spaced above the $(n, 3 n)$ reaction by the same spacing as that between the $(\pi, 2 n)$ and $(n, 3 n)$, approximately $6 \mathrm{MeV}$.

5. The elastic cross section was assumed to be 0.5 of the total cross section.

6. At each energy, the least well-known cross section was adjusted to make the sum of the partial cross sections equal the totai cross section. The requi rement of smooch vartation was 1mposed on the changes .

7. Because the transport program was not aet up to handle $(n, 4 n)$ and $(n, 5 n)$ reactions, these were incorporated in the fission cross section by defining a new fission cross section: $\sigma_{n f}=\sigma_{f}+\sigma(n, 4 n)+$ $\sigma(n, 5 n)$.

8. Alsc, veff is redefined to be

$\bar{v}$ eff $=\frac{\sigma_{f}+h \sigma(n, 4 n)+5 \sigma(n, 5 n)}{\sigma_{f}+\sigma(n, 4 n)+\sigma(n, 5 n)}$. 
9. The elast1c scattering angular distrlbution to $14.6 \mathrm{MeV}$ was used at all higher energles in these calculations.

10. The fission neutron spectral temperature was taken to be $1.29 \mathrm{MeV}$.

11. The capture cross section $\sigma(a, \gamma)$ was assumed to be zero, as was the cross section for charged particle reactions.

12. For the emission spectrum for the ( $\left.n, n^{\prime} c\right)$ reaction and the reactions $(n, 2 n)$ and $(n, 3 n)$, the cross sections of the LLL Howerton compllation at 14.6 MeV were assumed.
Using these sules, the extrapolated cross sectiors (In barns) are:

\begin{tabular}{|c|c|c|c|c|c|c|c|}
\hline$\underset{(\mathrm{MeV})}{\mathrm{E}}$ & $\sigma_{T}$ & $\sigma_{\mathrm{nn}}$ & $\sigma_{n^{\prime} c}$ & $\sigma_{n 2 n}$ & $\sigma_{n 3 n}$ & $\sigma_{\mathrm{nF}}$ & veff \\
\hline 17 & 6.04 & 3.10 & 0.24 & 0.3 & 1.10 & 1.30 & 4.92 \\
\hline 20 & 6.18 & 3.09 & 0.10 & 0.1 & 1.18 & 1.71 & 5.14 \\
\hline 23 & 6.05 & 3.00 & 0.0 & 0.0 & 0.6 & 2.45 & 5.36 \\
\hline 26 & 6.05 & 3.00 & 0.0 & 0.0 & 0.3 & 2.75 & 5.64 \\
\hline 30 & 5.81 & 2.90 & 0.0 & 0.0 & 0.1 & $2.8 i$ & 6.10 \\
\hline
\end{tabular}

APPENDIX B

TABULATED HIGH-ENERGY DATA

The tabulated results of the NMTC calculations are valuable because various other problems can be calculated using these as a source. From the discussion of Sec. III, it is apparent that nuclear effects in this model are not strongly mass or energy dependent. Indeed because the Inctdent particle energy is divided into small energy increments, to interpolate these results to slightly different energy values, an extrapolation proportional to E should be used. Similarly, besause the cascade views the nucleons as Individual particles, an extrapolation proportional to the nuclear mass (A) number should be used. Figure 2 is an example of the correctness of the former conjecture. The lines for $\mathrm{Sn}$ through U. If extrapolated back, Intersect at a point displaced from the origin by $100 \mathrm{MeV}$. Whether or not the rule stated for the A dependence is useful, is not clear. Table III shows that $n / p=0.7$ for 2310 , whereas $n / p=0.9$ for lead, but this difference could be due to spectral differences such as caused by $\left(n, n^{\prime} \gamma\right)$ and $(n, x n)$ reactions.

Tatle B-Ia presents a summary of cascade neutrons for Problems 1 through 7, excluding 6. Table B-Ib presents a sumary of the evaporation protow and neutrons for the same protlems. Sirflarly, Tablea B-rIa and b apply to Problen 6. Tables BIIİa and b apply to Problems 8 and 9 . Tables B-IVa and b apply to Problem 10, the Colubia Univeraty Nevis target, and Tables B-Va and b aply to Proble 11. The spatial groups used in the afx tables are $1 / 10$ th of the full size of the dimension under consideration; the enorgy spectrue groups are in intervals of $1 \mathrm{MeV}$ from 0 to $50 \mathrm{MeV}$. 
TALE I-I0

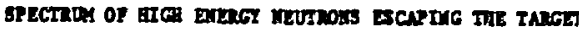

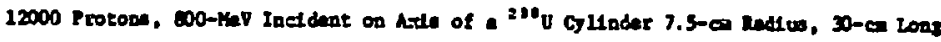

$A$ totel of 6533 vere produced

\begin{tabular}{|c|c|c|c|c|c|c|c|c|c|c|c|c|c|c|}
\hline Loery & 0 & 33.56 & 48.19 & 60.00 & 70.53 & $0 . \$ 1$ & 90.00 & 99.39 & 109.47 & 220.03 & 131.81 & 146.44 & 100.00 & Toen 1 \\
\hline 25 & 68 & 102 & 111 & 99 & 200 & 101 & 87 & 39 & 69 & 42 & 37 & 26 & & 901 \\
\hline 30 & 89 & 157 & 160 & 156 & 144 & 125 & 128 & 99 & 91 & 73 & 48 & 35 & & 1307 \\
\hline 40 & As & 222 & 256 & 121 & 145 & 111 & 76 & 67 & 39 & 41 & 21 & 26 & & 2038 \\
\hline 50 & 0 & $2 \ln$ & 119 & 100 & 75 & 68 & 62 & 43 & 37 & 30 & 16 & 18 & & 756 \\
\hline 60 & 83 & 87 & 87 & 83 & 88 & so & 35 & 35 & 26 & 21 & 11 & 7 & & 617 \\
\hline 70 & ss & 65 & 73 & $\mathbf{8 6}$ & 39 & 39 & 30 & 28 & 26 & 23 & 11 & 9 & & 502 \\
\hline 0 & 62 & 72 & 71 & 58 & 45 & 41 & 37 & 22 & 16 & $\boldsymbol{u}$ & 10 & 12 & & 447 \\
\hline 90 & 47 & 62 & 41 & 59 & 49 & 31 & 25 & 12 & 11 & 5 & 7 & 3 & & 352 \\
\hline 100 & 104 & 165 & 128 & 127 & 87 & 56 & 36 & 28 & 15 & 12 & 3 & 3 & & 724 \\
\hline 125 & 86 & 100 & 105 & $5:$ & 46 & 40 & 18 & is & 10 & 1 & 2 & 2 & & 493 \\
\hline 150 & 88 & 94 & 65 & 31 & 30 & 19 & 16 & 11 & 3 & 1 & 0 & 1 & & 35 \\
\hline 175 & 73 & 68 & 47 & 42 & 19 & 7 & 9 & 4 & 0 & 1 & $I$ & 0 & & 271 \\
\hline 200 & 51 & 57 & 35 & 17 & 11 & 3 & 1 & 1 & 0 & 0 & 0 & 0 & & 176 \\
\hline 225 & 40 & 47 & 17 & 17 & 7 & 2 & 0 & 2 & 1 & 0 & 0 & 0 & & 133 \\
\hline 250 & 71 & 67 & 43 & 13 & 5 & 5 & 0 & 1 & 0 & 0 & 0 & 0 & & 205 \\
\hline 300 & 64 & 3 & 20 & 5 & 2 & 0 & 0 & 0 & 0 & 0 & 0 & 0 & & 126 \\
\hline 350 & 40 & 24 & 10 & 1 & 1 & 0 & 0 & 0 & 0 & 0 & 0 & 0 & & $x$ \\
\hline 400 & 43 & 14 & 4 & 1 & 0 & 0 & 0 & 0 & 0 & 0 & 0 & 0 & & 62 \\
\hline 450 & 19 & 8 & 3 & 1 & 0 & 0 & 0 & 0 & 0 & 0 & 0 & 0 & & $\mathbf{n}$ \\
\hline 500 & 41 & 6 & 1 & 0 & 0 & 0 & 0 & 0 & 0 & 0 & 0 & 0 & & 42 \\
\hline 600 & 21 & 3 & 0 & 0 & 0 & 0 & 0 & 0 & 0 & 0 & 0 & 0 & & 24 \\
\hline $\begin{array}{l}700 \\
\infty 00\end{array}$ & 5 & 0 & 0 & 0 & 0 & 0 & 0 & 0 & 0 & 0 & 0 & 0 & & $s$ \\
\hline Total & 1325 & 1635 & 1294 & 1072 & 913 & 698 & 534 & 430 & 362 & 263 & 165 & 142 & & \\
\hline
\end{tabular}

TANLE B-Ib

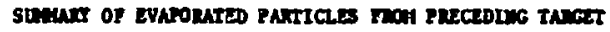

Eveporaction Spectre for 12301 Rrotod

Particle spectru from tiadial pist

$\begin{array}{llllllllll}12595 & 261 & 143 & 97 & 56 & 58 & 28 & 24 & 24 & 15\end{array}$

Langth Det in biretson of Inet deat wae

$\begin{array}{llllllllll}4439 & 3219 & 2003 & 125 & 757 & 362 & 16 & 49 & 13 & 17\end{array}$

Earas spectro

$\begin{array}{rrrrrrrrrr}0 & 0 & 0 & 0 & 0 & 0 & 0 & 4 & 216 & 1346 \\ 2205 & 1890 & 2576 & 2200 & 905 & 708 & 313 & 244 & 25 & 201 \\ 150 & 124 & 90 & 67 & 65 & 30 & 28 & 24 & 20 & 14 \\ 7 & 4 & 5 & 5 & 1 & 1 & 1 & 4 & 2 & 3 \\ 1 & 0 & 0 & 0 & 0 & 2 & 1 & 0 & 0 & 0\end{array}$

Eoparation spaetro for 253126 veutrous

Particle spactru fron Rediel DLet

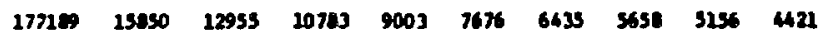

Lageh Dist in ol rection of Inclene teen

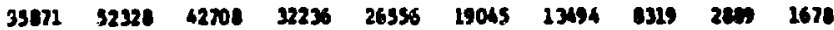

Eupro specern

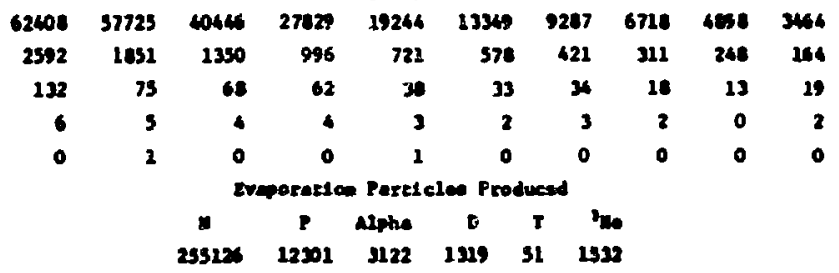

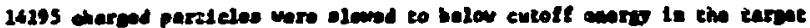


TALE A-1L

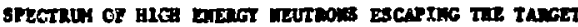

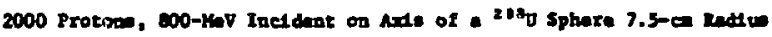

$A$ rocel of 1395 wore prodoced

\begin{tabular}{|c|c|c|c|c|c|c|c|c|c|c|c|c|c|}
\hline Inaxy & $\mathbf{0}$ & 33.56 & 48.19 & 60.00 & 70.53 & 0.41 & 90.90 & 99.59 & 109.47 & 120.00 & 131.81 & 14.4120 .00 & Totel \\
\hline 25 & 14 & 12 & 21 & 13 & $\mathbf{a}$ & 6 & 9 & 9 & 4 & 7 & 6 & 2 & 111 \\
\hline 30 & 40 & 39 & 21 & 20 & 26 & 29 & 19 & 13 & 7 & 10 & $s$ & 3 & 226 \\
\hline 40 & 32 & 21 & 22 & 13 & 9 & 8 & 9 & 3 & - & 5 & 2 & 3 & 153 \\
\hline 50 & 19 & 15 & 16 & 9 & 15 & 8 & 8 & 2 & 1 & 5 & 2 & $\mathbf{0}$ & $\boldsymbol{9}$ \\
\hline 60 & 26 & 25 & 10 & 14 & 8 & 6 & 2 & 0 & 4 & 1 & 0 & 0 & 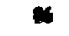 \\
\hline 70 & 19 & 9 & 13 & 8 & 5 & 7 & 1 & 4 & 2 & 0 & 1 & 0 & 6 \\
\hline $\mathbf{0 0}$ & 15 & 7 & 12 & 6 & 12 & 9 & 3 & 2 & 2 & 3 & 1 & 1 & 73 \\
\hline 90 & 11 & 12 & 13 & 8 & 7 & 3 & 2 & 2 & 0 & 0 & 1 & 0 & 5 \\
\hline 100 & 25 & 19 & 17 & $\mathfrak{1}$ & $\mathbf{B}$ & 7 & 7 & 0 & 5 & 4 & 1 & 0 & 106 \\
\hline 125 & 23 & 26 & 14 & 26 & 16 & 2 & 5 & 1 & 2 & 1 & 1 & 1 & 102 \\
\hline 150 & 17 & 17 & 12 & 9 & 6 & 4 & 0 & 2 & 2 & 0 & 0 & 0 & 6 \\
\hline 175 & 12 & 4 & 10 & 2 & 7 & 0 & 1 & 1 & 0 & 0 & 0 & 0 & 37 \\
\hline 200 & 22 & 12 & 7 & 5 & 3 & 0 & 1 & 0 & 0 & 0 & 0 & 0 & 50 \\
\hline 225 & 14 & 9 & 4 & 2 & 1 & 1 & 1 & 0 & 0 & 0 & 0 & 0 & 32 \\
\hline 250 & 27 & 10 & 6 & 2 & 1 & 0 & 0 & 0 & 0 & 0 & 0 & 0 & 46 \\
\hline 360 & 16 & 12 & 2 & 0 & 0 & 0 & 0 & 0 & 0 & 0 & 5 & 0 & 30 \\
\hline $\begin{array}{l}350 \\
400\end{array}$ & 9 & 1 & 2 & 0 & 0 & 0 & 0 & 0 & 0 & 0 & 0 & 0 & 12 \\
\hline 450 & 7 & 3 & 0 & 1 & 0 & 0 & 0 & 0 & 0 & 0 & 0 & 0 & 11 \\
\hline $\begin{array}{l}450 \\
500\end{array}$ & 9 & 0 & 0 & 0 & 3 & 0 & 0 & 0 & 0 & 0 & 0 & 0 & 5 \\
\hline $\begin{array}{l}200 \\
600\end{array}$ & 18 & 1 & 0 & 0 & 0 & 0 & 0 & 0 & 0 & 0 & 0 & 0 & 19 \\
\hline 20 & 10 & 0 & 0 & 0 & 0 & 0 & 0 & 0 & 0 & 0 & 0 & 9 & 10 \\
\hline $\begin{array}{l}70 \\
00\end{array}$ & 1 & 0 & 0 & 0 & 0 & 0 & 0 & 0 & 0 & 0 & 0 & 0 & .1 \\
\hline Toral & 382 & 262 & 200 & .37 & 130 & $\boldsymbol{\alpha}$ & 68 & 39 & 37 & 3 & 20 & 10 & \\
\hline
\end{tabular}

TALE E-ITb

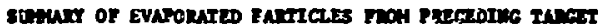

Eveporatisa Spectra for 16m Proton

Particle spectro from Radiel biet

$\begin{array}{llllllllll}1637 & 18 & 15 & 3 & 2 & 2 & 1 & 2 & 0 & 0\end{array}$

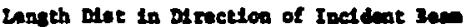

$\begin{array}{llllllllll}0 & 0 & 0 & 325 & 339 & 316 & 292 & 198 & 201 & 120\end{array}$

Anero Bpastru

$\begin{array}{rrrrrrrrrr}0 & 0 & 0 & 0 & 0 & 0 & 0 & 0 & 30 & 223 \\ 271 & 279 & 199 & 161 & 131 & 110 & 64 & 54 & 20 & 27 \\ 21 & 19 & 14 & 10 & 13 & 6 & 3 & 2 & 3 & 2 \\ 1 & 2 & 1 & 2 & 1 & 0 & 2 & 0 & 0 & 0 \\ 0 & 1 & 0 & 0 & 0 & 0 & 0 & 0 & 0 & 0\end{array}$

Eveporation Spactre for 26699 reutzon

Paredals spectro froe redial biat

$\begin{array}{llllllllll}21763 & 1339 & 1245 & 713 & 635 & 392 & 273 & 226 & 150 & 6\end{array}$

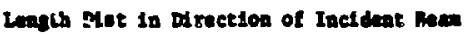

$\begin{array}{llllllllll}2 & 52 & 59 & 3702 & 6929 & 4705 & 3467 & 3295 & 3244 & 2746\end{array}$ Eocro spactru

$\begin{array}{rrrrrrrrrr}5124 & \text { s45 } & 4246 & 2991 & 2171 & 2561 & 1046 & 242 & 653 & 461 \\ 310 & 233 & 172 & 114 & 63 & 73 & 61 & 42 & 25 & 27 \\ 14 & 12 & 9 & 6 & 7 & 10 & 7 & 3 & 1 & 6 \\ 1 & 0 & 1 & 0 & 0 & 0 & 0 & 0 & 1 & 0 \\ 0 & 0 & 0 & 0 & 0 & 0 & 0 & 0 & 0 & 0\end{array}$

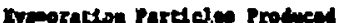

1 I Alete $D$ the

aces. yos 49200 \& 221

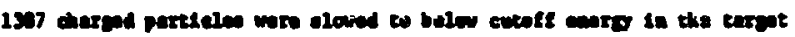


TAUS B-IIIS

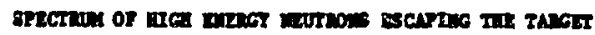

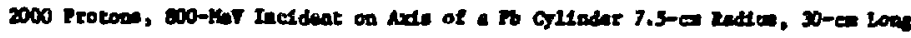

A totel of 1700 wart probeed

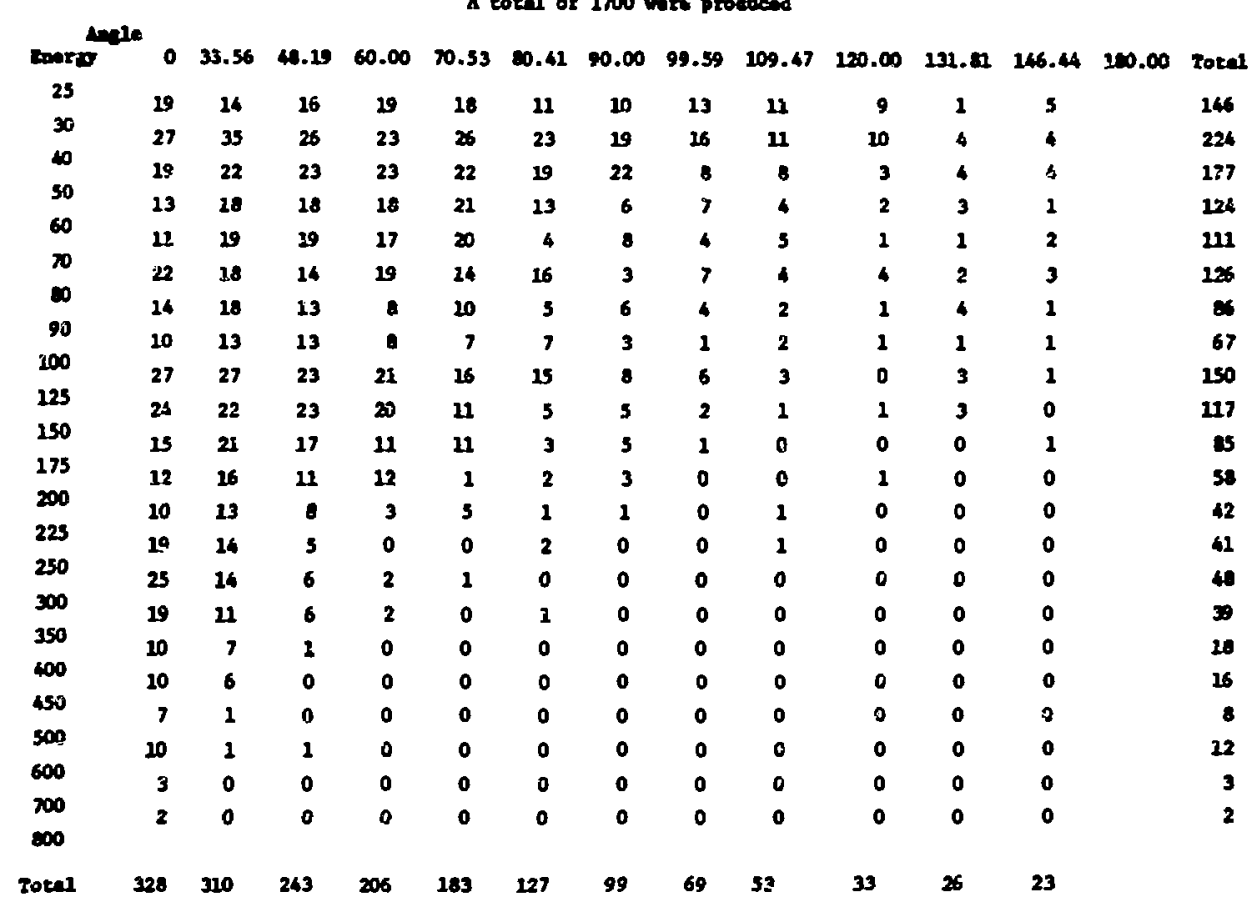

TALE B-IITB

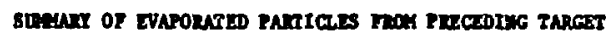

Exaporatioa Bpactra for 2205 Protone and 29855 vautrons

Part1cie spectrut troo Endiel Diet

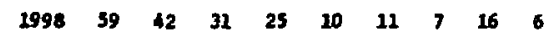

Length Diec in Di rection of Incldeat sem

$\begin{array}{llllllllll}519 & 461 & 333 & 255 & 227 & 116 & 99 & 97 & 70 & 29\end{array}$

bunts spactron

$\begin{array}{rrrrrrrrrr}0 & 0 & 0 & 0 & 0 & 0 & 1 & 11 & 150 & 304 \\ 360 & 324 & 219 & 190 & 148 & 124 & 79 & 60 & 46 & 38 \\ 32 & 25 & 19 & 17 & 13 & 9 & 11 & 4 & 3 & 7 \\ 4 & 2 & 1 & 0 & 1 & 0 & 1 & 0 & 0 & 0 \\ 0 & 0 & 0 & 0 & 0 & 0 & 0 & 1 & 0 & 0\end{array}$

Particle spectru froe hedial Det:

$\begin{array}{lllllllll}21897 & 1696 & 1325 & 971 & 823 & 687 & 357 & 639 & 450\end{array}$

Lanth Dot in DArection of Inchdent Iem

$\begin{array}{llllllllll}4756 & 4942 & 4195 & 3732 & 3154 & 2513 & 2036 & 2032 & 1476 & 959\end{array}$

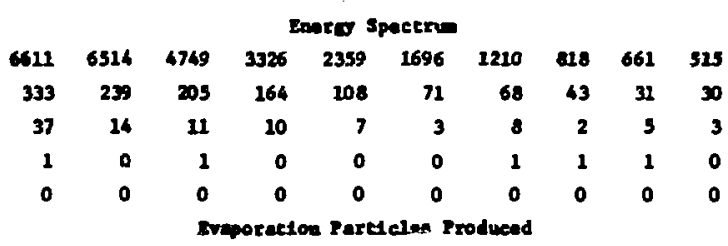

Evaporacton Particien Froduced

$\begin{array}{cccccc}1 & P & \text { Aphe } & D & T & 21 \\ 20155 & 2205 & 462 & 121 & 9 & 17\end{array}$

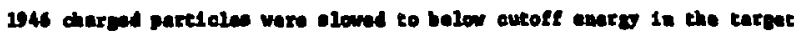


TNe B-IVa

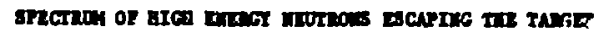

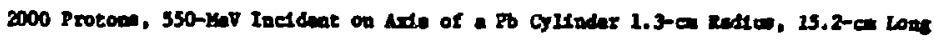

4 total of 1105 vere produced

\begin{tabular}{|c|c|c|c|c|c|c|c|c|c|c|c|c|c|c|}
\hline $\operatorname{lom} x$ & 0 & 33.56 & 48.19 & 60.00 & 70.53 & 0.41 & 90.00 & 99.59 & 109.47 & 120.00 & 131.81 & 146.44 & 180.00 & Tocel \\
\hline 25 & 16 & 13 & 12 & 11 & 6 & 7 & 7 & 6 & 4 & 2 & 1 & 2 & & 67 \\
\hline 30 & 23 & 13 & 20 & 23 & 17 & 9 & 8 & 9 & 2 & 4 & 3 & 3 & & 130 \\
\hline 40 & 11 & 19 & 17 & 21 & 26 & 34 & 6 & 5 & 3 & 3 & 2 & 1 & & 218 \\
\hline 50 & 16 & 14 & 11 & 17 & 15 & 11 & 5 & 6 & 3 & 3 & 1 & 1 & & 102 \\
\hline 60 & 12 & 12 & 11 & 10 & 4 & 10 & 5 & 5 & 1 & 2 & 1 & 0 & & 73 \\
\hline$m$ & B & 13 & 13 & 8 & 36 & 3 & 2 & 4 & 3 & 0 & 0 & 0 & & 60 \\
\hline 60 & 11 & 7 & 7 & 12 & 5 & 2 & 2 & 5 & 0 & 0 & 0 & 0 & & 51 \\
\hline 90 & 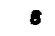 & 9 & 5 & 9 & 3 & 2 & 2 & 0 & 1 & 0 & 1 & 0 & & 40 \\
\hline 100 & 19 & i7 & 17 & 12 & 9 & 7 & 4 & 0 & 1 & 0 & 0 & 0 & & 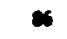 \\
\hline 125 & 23 & 17 & 14 & $\theta$ & 9 & 3 & 2 & 0 & 0 & 0 & 0 & 0 & & $x$ \\
\hline 150 & 14 & 20 & 15 & 8 & 0 & 1 & 1 & 0 & 0 & 0 & 0 & 0 & & 5 \\
\hline 175 & 15 & 12 & 8 & 3 & 3 & 0 & 1 & 1 & 0 & 0 & 0 & 0 & & 43 \\
\hline 200 & 12 & 7 & 5 & 1 & 1 & 1 & 0 & 0 & 0 & 0 & 0 & 0 & & 27 \\
\hline 225 & 12 & 7 & 2 & 0 & 1 & 0 & 0 & $a$ & 0 & 0 & 0 & 0 & & 22 \\
\hline 250 & 31 & 11 & 4 & 2 & 0 & 0 & 0 & 0 & 0 & 0 & 0 & 0 & & 48 \\
\hline 300 & $\mathbf{u}$ & 15 & 1 & 0 & 0 & 0 & 0 & 0 & 0 & 0 & 0 & 0 & & 27 \\
\hline 350 & 22 & 1 & 1 & 0 & 0 & 0 & 0 & 0 & 0 & 0 & 0 & 9 & & 14 \\
\hline 400 & 16 & 2 & 0 & 0 & 0 & 0 & 0 & 0 & 0 & 0 & 0 & 0 & & 18 \\
\hline 450 & 5 & 0 & 0 & $\mathbf{0}$ & 0 & 0 & 0 & 0 & 0 & 0 & 0 & 0 & & 5 \\
\hline 500 & 3 & 0 & 0 & 0 & 0 & 0 & 0 & 0 & 0 & 0 & 0 & 0 & & 3 \\
\hline 600 & 0 & 0 & 0 & 0 & 0 & 0 & 0 & 0 & 0 & 0 & 0 & 0 & & 0 \\
\hline $\begin{array}{l}\infty 00 \\
000\end{array}$ & 0 & 0 & 0 & 0 & 0 & 0 & 0 & 0 & 0 & 0 & 0 & 0 & & 0 \\
\hline Total & 276 & 214 & 163 & 145 & 103 & 70 & 45 & 41 & 28 & 14 & 9 & 7 & & \\
\hline
\end{tabular}

TABLe 2-IV

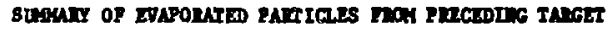

Bveporation spactra for 250 Protons ad 13241 itentrow

Fartlele Spoctro tros redial bet

B18 742146431

Length Diot in Diraction of Inetdent seco

$\begin{array}{llllllllll}122 & 151 & 342 & 109 & 81 & 62 & 49 & 62 & 39 & 33\end{array}$

Ears Spactro

$\begin{array}{rrrrrrrrrr}0 & 0 & 0 & 0 & 0 & 0 & 0 & 1 & 53 & 116 \\ 137 & 139 & 103 & 79 & 66 & 34 & 27 & 21 & 31 & 12 \\ 6 & 8 & 6 & 2 & 2 & 1 & 3 & 1 & 1 & 1 \\ 0 & 0 & 0 & 0 & 0 & 0 & 0 & 0 & 0 & 0 \\ 0 & 0 & 0 & 0 & 0 & 0 & 0 & 0 & 0 & 0\end{array}$

Porticle Spectro tron Endial Det

$\begin{array}{llllllllll}12059 & 141 & 115 & 115 & 142 & 122 & 149 & 129 & 227 & 202\end{array}$

Lanth Dist in Bractlon of Ineldent Iaw

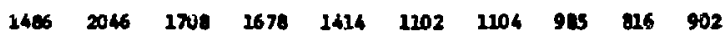

Inarg spectrue

$\begin{array}{rrrrrrrrrr}2898 & 2243 & 2234 & 2547 & 1124 & 760 & 520 & 374 & 260 & 205 \\ 139 & 84 & 71 & 56 & 27 & 24 & 18 & 9 & 13 & 10 \\ 9 & 2 & 5 & 2 & 1 & 1 & 0 & 0 & 0 & 1 \\ 0 & 0 & 0 & 0 & 0 & 0 & 1 & 0 & 0 & 0 \\ 0 & 0 & 0 & 0 & 0 & 0 & 0 & 0 & 0 & 0\end{array}$

Ireporatsion Rarticles Froduced

4 R Nithe $D$ in.

$\begin{array}{llllll}23341 & 50 & 147 & 4 & 2 & 45\end{array}$

628 cherged patteles wro olowed to balow cutoll anry in the tarnt 
Tane :-7a

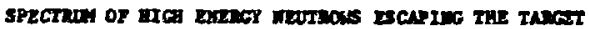

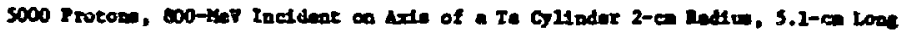

a cotel of 2512 vore producad

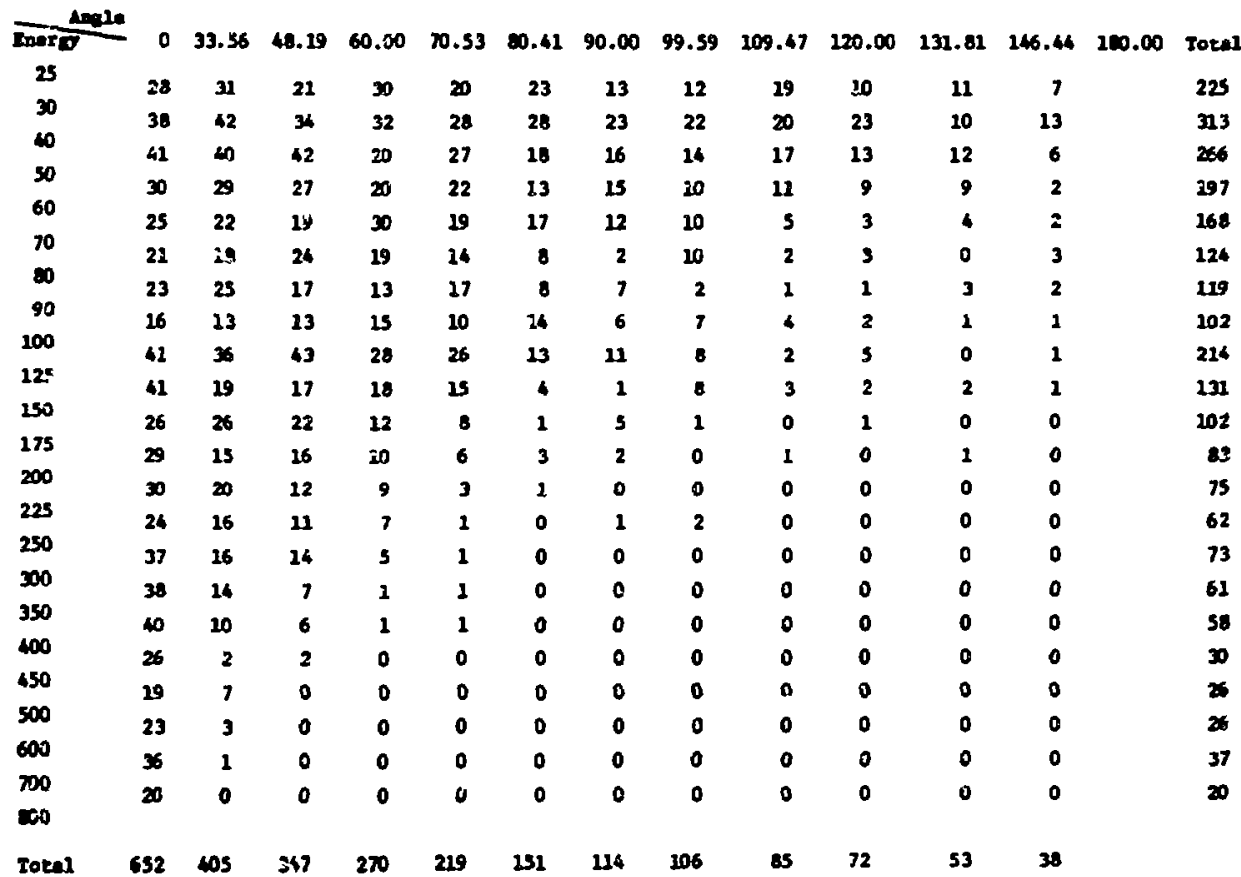

TABDE $D-W$

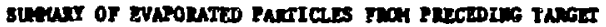

Leporaston Spactre for 3106 Protone

Partialo Spaetrin from pailal Dat

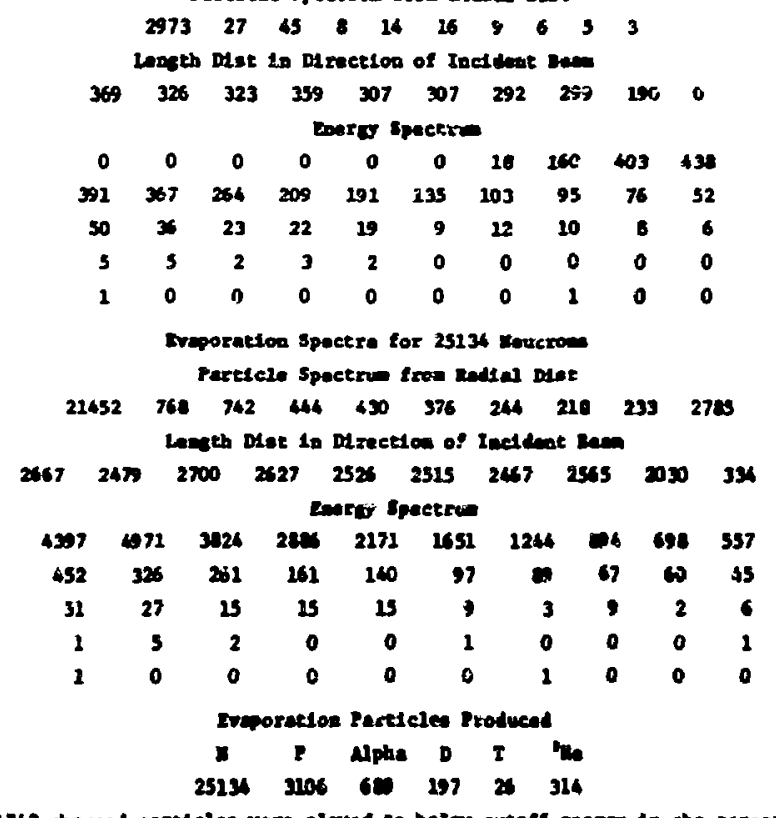

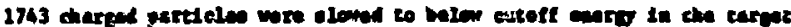




\section{REFERENCES}

1. W. W. Havens, "Cyclotrons, Synchrocyclotrons, and Synchrotrons as Pulsed High Intensity Neutron Sources," Seminar on Intense Neutron Sources, Sant Be, MM, September 19-23, 1966 , CONF-669025, p. 565.

2. G. A. Bartholomew, Proceedinge of the International Conference on the Study of Nuclear Structure with Neutrons, Antwerp 1965 (North Holland Publishing Co., Amsterdam, 1966), p. 458 .

3. W. A. Gibson, A. Zucker, E. G. Gross, J. F. Fraser, R. E. Green, J. H. HLlborn, and J. C. D. M1lon, Oak R1dge National Laboratory Report ORNL-3940, p. 110 (1966).

4. R. Sexber, Phys. Rev. 22, 1114 (1947).

5. 14. L. Golberger, Phys. Rev. 74, 1269 (1948).

6. G. Bernardint, E. T. Booth, and S, J. Lindenbaum, Phys. Rev. 89, 1017 (1952).

7. G. C. Morrison, H. Mutrhead, and W. G. V. Rosser, Ph11. Mag. 46, 1326 (1953).

8. h. Mclanus, W. I. Sherp, and H. Geliman, Phys. Rev. 93, 924A (1954).

9. J. W. Meadows, Phys. Rev. 98, 744 (1955).

10. J. Conbe, Nuovo Cimento 3, 5182 (1956).

11. G. Ruistan, PhD Thesis, Unt versity of Uppeala, Uppeala, Sireden, 1956 (unpublished).

12. N. S. I vanova and I. I. P1anov, JGTP 4, 367 (1957).

13. R. Metropolls, R. Pevins, M. Storm, A. Turkevich, J. M. Miller, and G. Friedlander, Phys. Rev. 110, 185 (1958).

14. H. W. Bertint, Phya. Rev. 131, 1801 (1963) and erratur Phys. Rev. 138 AB2 (1965).

15. W. E. Kinney, Oak R1dge National Lboratory Report ORNh-3610 (1964).

16. W. A. Coleman and T. W. Armetrons, Oak Ridge iat' onal Leboratory Raport ORRT-4606 (1970).

17. V. F. Weisskopf, Phye. Rov. 52, 295 (1937).

18. I. Dostroveky, 2. Freenkel, and G. Friediander, Phys. Rev. 116, 683 (1959).

19. L. Dresner, Oul Ridge National Leboratory Report ORNL-CF-6I-12-30 (1961).

20. M. P. Guthr1e, Oak R1dge Hational Lboratory Roport ORHL-TH-3119 (1970).

21. H. W. Bertin1, "Calculation of Huclear Reaction for Incldent Nucleone and $\pi$ Hason In the Enerey Range 30 to $2700 \mathrm{MV}$," preaented at the International Conference on Radintion ShIelding and Doelmetry, Stenford, $\mathrm{CA}$, Noverber 1970.

2. O5R-Radiation Shieldins Inforation Ceriter Report $\operatorname{CCC}-17$, Dak RAdze, TH.

23. E. D. Camwe 11 and G. D. Turner, Los Alans Lelent1f1.C Leboratory Paport LA-4751 (to be poblished).

24. 2 G. Schrendt, J. D. Gramer, and J. R. Beyotur, "Inrget Studle for Meutron Iroduction on Limp," wo Nlewos scteatifle Leboratory internal emorande April 3, 1970.
25. H. W. Bert1nt, Nucl. Phys. 87, 138 (1966).

26. H. H. Berint, Q - 2. Bishop, and M. P. Guthale, Oak R1dge National Laboratory Report ORHL-4128 (1967).

27. H. W. Bertind and M. P. Guthrie, Ock Ridge National Laboratory Report ORNL-TI-3336 (1970).

28. R. G. Alswller, Jr., and J. Bartah, Oak Mége NatLonel Laboratory Report ORIL-TI-2277 (1968).

29. K. G. Alendler, Jr., M. Letmdorfer, and J. Barish, Oak Ridge Nationul Laboratory Report ORRL-4046 (19667).

30. R. C. Alsmiller, Jr, and J. Bartsh, Ock R1dre National Luboratory Report ORHL-4220 (1968).

31. R. G. Alomiller, Jr., F. R. Hynte, J. Bartsh, and $W$. W. Engle, Jr., Nucl. Sct. Eng. 36, 251 (1969).

32. R. G. Alsailler, Jr., F. R. Hyatt, J. Barteh, and W. W. Engle, Jr., Ork Ridge kationsl Lboratory Report ORRI-TH-2554 (1969).

33. W. A. Colenan and R. G. Alsailler, Jr., Kucl. Sct. Eng. 34, 1C4 (1963).

34. I. C. D. Milion and J. S. Fraeer, Atonte Eners of Canada Ltd. Report AECL-2259 (1965).

35. J. S. Fraser. 1. S. Bewtet, and J. Walker, "Neutron Spectra and Angular Distribution Produced by $1 \mathrm{GeV}$ Proton on a Thick Lead Target," paper presented at the Congrest-Canudim Asooctation of Physictste, Shertrooke, Quobec, Canade (1966). Gelin Institute Nuber 66-221-4.

36. L. R. Veeser, Los Alemos Scientific Luboratory, private coununication to R. R. Fullwood (1971).

37. A. A. Robba, R. P. Fullwcod, and L. R. Peeser, Los Alawos Sclentific Leboratory Report LA-DC12314 (1971) to epear in Anericen Auclear Socitety Report Nis-SD-12.

38, R. G. Alsind11ex, Jx., and G. S. Kerm, Muck. Inetr. Kethods 48,109 (1967).

39. D. W. Groce, Gulf Gaceral Azonic Ieport GA-8087 (1967).

40. R. G. Alontller, Jr., T. A. Gabriel, and M. P. Guthr1., Nucl. Sal. Enc. 40, 365 (1970).

41. E. R. Ra (AERE Herwe11, En land), private conunication to R. R. Fullwood (1966).

42. R. I. Mack11n, Nusil. Intr. Nathod 91. 79 (1971).

43. R. R. Fullwood, "Uxins a rmon Factors a m Intense Pulsed Feutron Source," Inerican Huclear Soctety National Topical Heetrs. Atlence, G (1971), CO:A 710402 .

44. N. C. Pertins and T. A. keugle, Itex Treas. Huel. Sci. AS-16, 316 (1969).

45. J. Rafinater, IEEE Trape. Nuel. Sct. M-18, 252 (1971).

46. R. E. Huater, J. H. Berl1jn, and C. C. Crane Los Alanse Setentific Lebratory peport $\mathrm{L}$-3527 (1968).

Aratar: $500(206)$ 